Article

\title{
Synthesis and Antiangiogenic Activity of Novel Gambogic Acid Derivatives
}

Tao Chen ${ }^{1}$, Rong-Hong Zhang ${ }^{1}$, Shi-Chao He ${ }^{2}$, Qin-Yuan Xu ${ }^{1}$, Liang Ma ${ }^{1}$, Guang-Cheng Wang ${ }^{1}$, Neng Qiu ${ }^{1}$, Fei Peng ${ }^{1}$, Jin-Ying Chen ${ }^{1}$, Jing-Xiang Qiu ${ }^{1}$, Ai-Hua Peng ${ }^{1}$ and Li-Juan Chen ${ }^{1, *}$

1 State Key Laboratory of Biotherapy, West China Hospital, West China Medical School, Sichuan University, Chengdu, Sichuan 610041, China

2 School of Chemical Engineering, Sichuan University, Chengdu, Sichuan 610065, China

* Author to whom correspondence should be addressed; E-Mail: lijuan17@hotmail.com; Tel.: +86-28-8516-4063; Fax: +86-28-8516-4060.

Received: 16 April 2012; in revised form: 4 May 2012 / Accepted: 9 May 2012 /

Published: 25 May 2012

\begin{abstract}
Gambogic acid (GA) is in a phase II clinical trial as an antitumor and antiangiogenesis agent. In this study, 36 GA derivatives were synthesized and screened in a zebrafish model to evaluate their antiangiogenic activity and toxicity. Derivatives 4, 32, 35, 36 effectively suppressed the formation of newly grown blood vessels and showed lower toxicities than GA as evaluated by zebrafish heart rates and mortalities. They also exhibited more potent migration and HUVEC tube formation inhibiting activities than GA. Among them, 36 was the most potent one, suggesting that it may serve as a potential new antiangiogenesis candidate with low toxicity. Additionally, 36 showed comparable antiproliferative activity to HUVECs and five tumor cell lines but low cytotoxicity to LO2 cells.
\end{abstract}

Keywords: gambogic acid; antitumor; antiangiogenesis; zebrafish; toxicity

\section{Introduction}

Angiogenesis, or new blood vessel growth, is defined as a process in which a network of new blood vessels emerge from preexisting vessels. The inhibition of angiogenesis is a promising tool to fight cancer [1]. Tumor angiogenesis, which involves multiple cellular processes including endothelial cell (EC) activation, invasion, migration, proliferation, tube formation and capillary network formation, is 
essential for cancer growth and metastasis [1-4]. Without the development and progression of new blood vessels, tumors can rarely grow over a few $\mathrm{mm}^{3}$ in size or metastasize to other organs $[5,6]$. Therefore, inhibition of angiogenesis is an important target for cancer therapy $[7,8]$.

The zebrafish (Danio rerio) screening model for anti-angiogenesis activity has become increasingly popular in different fields such as pharmacology, toxicology and developmental and evolutionary biology since the 1970s [9-11]. It is regarded as a powerful tool in the study of human diseases [9]. Indeed, zebrafish possess many advantages that make them a highly useful valid tumor model system for antiangiogenesis, including relatively small size (up to $3 \mathrm{~cm}$ ), low cost, and being easy to house and maintain in large quantities $[9,10]$. The application of transgenesis to the zebrafish resulted in the ability to spatially and temporally control gene expression and to create or increase in vivo imaging capabilities [9]. Transgenic zebrafish models expressing green fluorescent protein (GFP) in vascular endothelial cells (ECs) are significantly useful for studying the formation of the vasculature in vivo [12].

Cultured ECs are also widely appreciated tools in angiogenesis research [5]. ECs commonly used for more than 30 years now are human umbilical vein ECs (HUVECs) which are easily obtained and less prone to acquire drug resistance [11]. EC migration in vivo is indispensable for wound-healing as well as for the formation of new vessels [4]. The capacity of the ECs to form tube-like structures when cultured on a semi-natural matrix is another typical in vitro angiogenesis assay [2]. Therefore, the phenotype of tumor ECs is subject to investigation to identify putative target molecules for interference to discover novel angiogenesis-inhibiting agents.

Gambogic acid is a natural product isolated from the resin of the Garcinia hurburyi tree found in Southeast Asia. It is in a phase II clinical trial in China and is widely known as an antiangiogenesis and antitumor agent [13-19]. However, until now, no study has focused on the structural modification of GA to evaluate antiangiogenic activity and related toxicity. In this study, the antiangiogenic activities and toxicities of GA and GA derivatives were evaluated for the first time using a zebrafish screening model.

In this paper, we synthesized and screened 36 GA derivatives. Compounds 4, 32, 35, 36 effectively suppressed the formation of newly grown segmental blood vessels in the zebrafish-based assay and were less toxic to zebrafish compared to GA. These four derivatives also exhibited more potent inhibitory potencies against the migration and tube formation of HUVECs in vitro than GA. Importantly, among them, 36 was the most potent one, with a $98.3 \%$ migration inhibition rate and $100 \%$ tube formation inhibitory rate at a concentration of $2 \mu \mathrm{M}$, suggesting that this derivative may serve as a potential new antiangiogenesis candidate.

\section{Results and Discussion}

\subsection{Chemistry}

Gambogic acid was isolated from the easily and widely available gamboge resin in an overall yield of approximately $5 \%$. It was purified by changing the crude extract from the gamboge resin into a pyridine salt, followed by recrystallization [20]. There are many functional groups in the structure of GA which could potentially be modified such as 30-carboxy, 8-ketone, methyl group at C-35 or C-39, 6-hydroxy, 9,10-double bond in the $\alpha, \beta$-unsaturated ketone, carbon-carbon double bond at C-32/33 or C-37/38. However, earlier structure activity relationship (SAR) studies had identified that the 9,10-double 
bond in the $\alpha, \beta$-unsaturated ketone is critical for activity, and the modifications of 6-hydroxy and 8-ketone did not improve the activity dramatically [21,22]. Therefore, to develop novel GA derivatives as inhibitors of angiogenesis, we elected to modify the 30-carboxy and carbon-carbon double bond at C-32/33 and C-37/38.

The modification of the 30-carboxy group is depicted in Schemes 1, 2 and 3. Coupling of GA with various alcohols or phenols in the presence of DMAP and EDCI produced the corresponding GA esters 1-28 in 39\%-92\% yield (Scheme 1). Reaction of GA with two sulfhydryl compounds in the presence of DMAP and EDCI produced the corresponding GA thioesters 29-30 in 59\%-68\% yield (Scheme 2).

Scheme 1. Synthesis of derivatives 1-28.
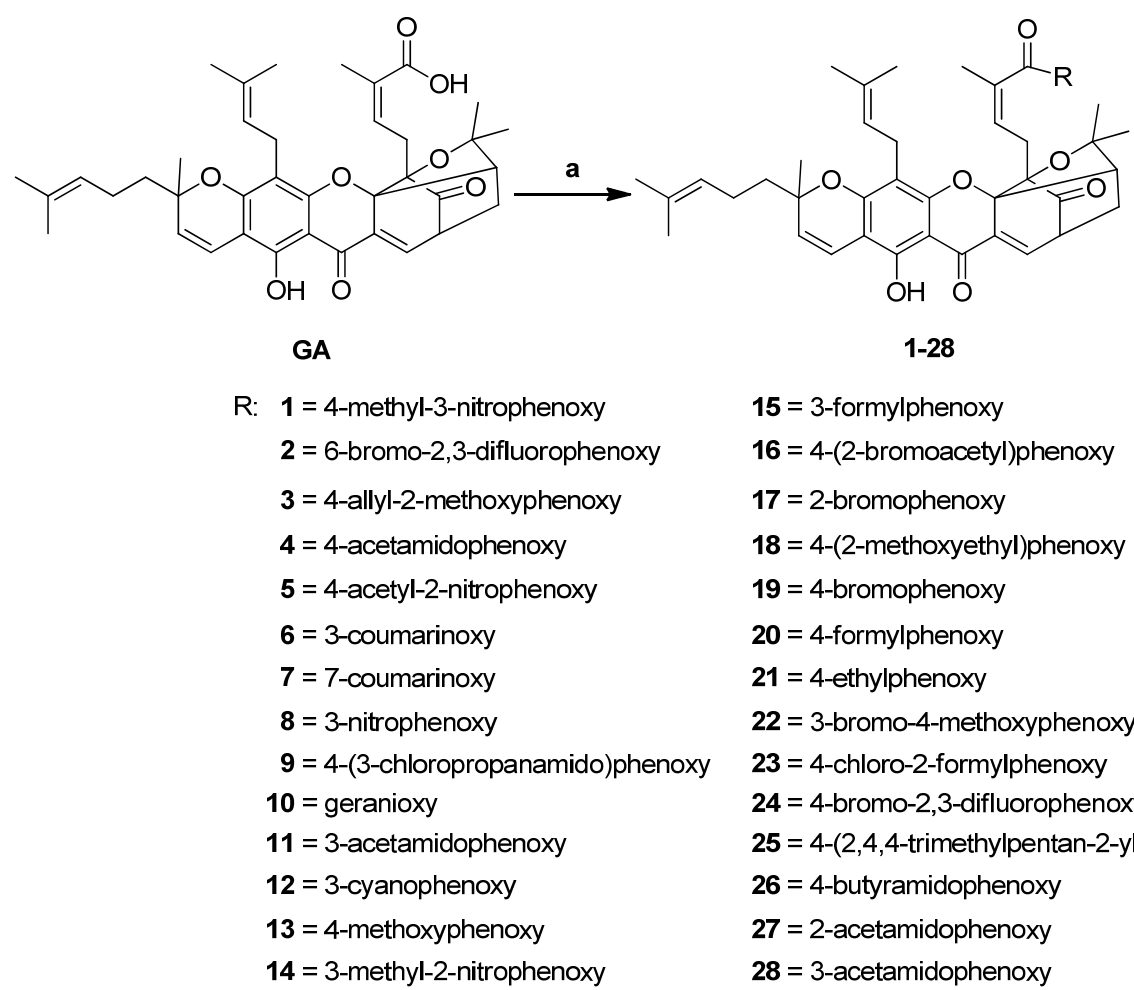

1-28

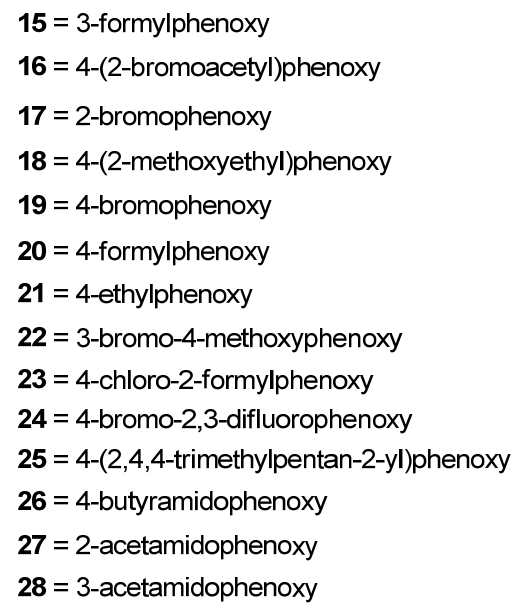

Reagents and conditions: (a) R-H (1.2 equiv.), DMAP (0.56 equiv.), EDCI (1.67 equiv.), $\mathrm{CH}_{2} \mathrm{Cl}_{2}$, $25^{\circ} \mathrm{C}$, overnight, $39-92 \%$.

Scheme 2. Synthesis of derivatives 29-30.

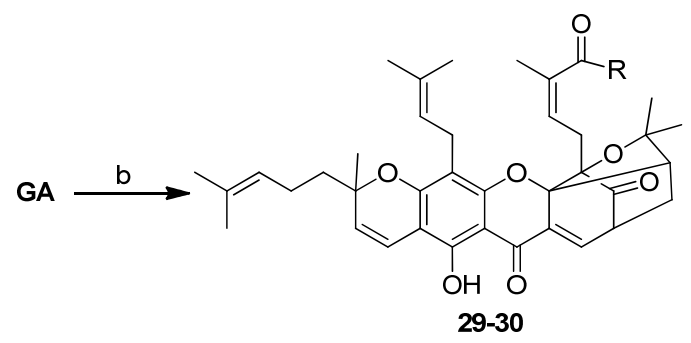

R: $\mathbf{2 9}=$ thiazole-2-thio

30 = 4-acetamidophenylthio

Reagents and conditions: (b) R-H (1.2 equiv.), DMAP (0.56 equiv.), EDCI (1.67 equiv.), $\mathrm{CH}_{2} \mathrm{Cl}_{2}$, $25^{\circ} \mathrm{C}$, overnight, $59-68 \%$. 
Reaction of GA with appropriate amines in the presence of DMAP and EDCI produced the corresponding amides of GA 31-35 in 49\%-73\% yield (Scheme 3 ).

Scheme 3. Synthesis of derivatives 31-35.

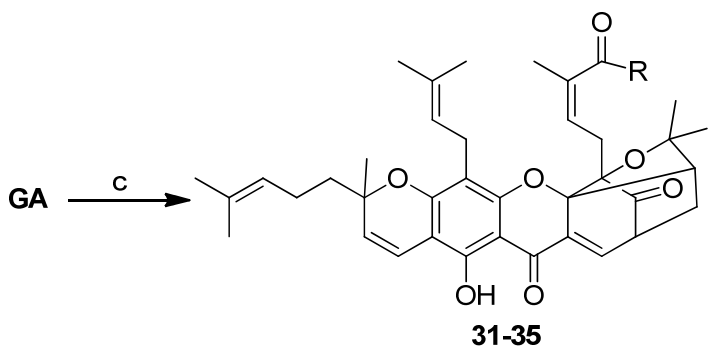

R: 31 = 4-(4-methoxyphenyl)thiazol-2-amino

$32=$ thiazol-2-amino

$33=$ pyrazol-1-yl

$34=$ benzo[d]thiazol-2-amino

$35=4$-acetamidoanilino

Reagents and conditions: (c) R-H (1.2 equiv.), DMAP (0.56 equiv.), EDCI (1.67 equiv.), $\mathrm{CH}_{2} \mathrm{Cl}_{2}$, $25^{\circ} \mathrm{C}$, overnight, $49-73 \%$.

The carbon-carbon double bonds at C-32/33 and C-37/38 were modified as shown in Scheme 4 [21]. Reaction of 35 with $m$-CPBA for about $6 \mathrm{~h}$ at $25{ }^{\circ} \mathrm{C}$, produced the GA derivative 36 containing two epoxy groups at C-32/33 and C-37/38 in 71\% yield.

Scheme 4. Synthesis of analogue 36.

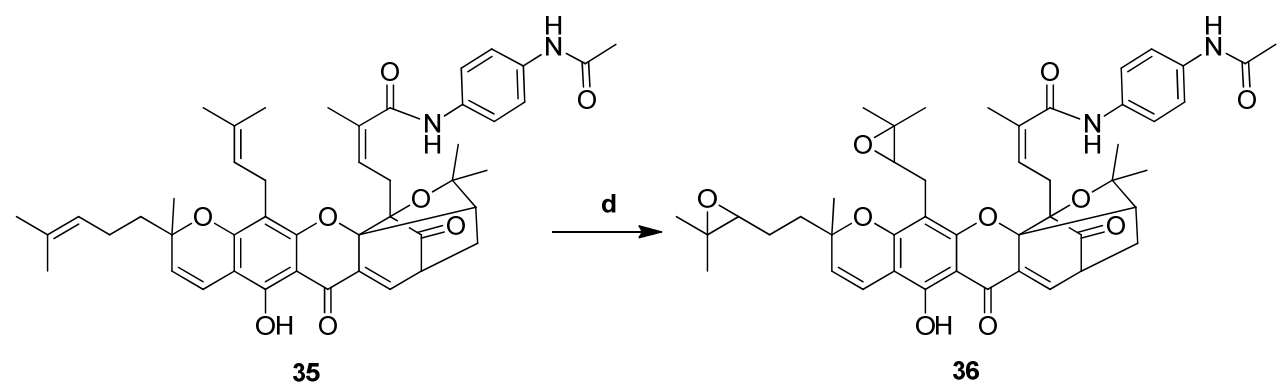

Reagents and conditions: (d) $m$-CPBA (2.25 equiv.), $\mathrm{CH}_{2} \mathrm{Cl}_{2}, 25{ }^{\circ} \mathrm{C}, 6 \mathrm{~h}, 71 \%$.

\subsection{Antiangiogenic Activity and Toxicity in the Transgenic Zebrafish Model}

As stated previously, zebrafish is regarded as a powerful tool in the study of human diseases. Transgenic zebrafish models expressing green fluorescent protein (GFP) in vascular endothelial cells (ECs) are significantly useful for studying the formation of the vasculature in vivo. In this study, all GA derivatives were incubated with the transgenic friend leukemia integration-1 (fli-l): enhanced GFP zebrafish embryos which carried a fli- 1 promoter which can drive the expression of GFP in the whole endothelium [23].

At a concentration of $1 \mu \mathrm{M}$, compounds 16, 20, 22, 23 and 31 were inactive, the antiangiogenic rates of compound 9 was less than $25 \%$, and the antiangiogenic rates of compounds 4, 26, 32, 35, 36 and GA were $25 \%-50 \%$ (Table 1). The remaining derivatives (not listed) were inactive even at concentrations exceeding $10 \mu \mathrm{M}$. However, GA caused zebrafish embryo death at concentrations of 
$2.5 \mu \mathrm{M}$ and $10 \mu \mathrm{M}$. The antiangiogenic activities of $\mathbf{9}$ and 26 were moderate at $2.5 \mu \mathrm{M}$ and not enhanced greatly when the concentration reached $10 \mu \mathrm{M}$.

Table 1. Antiangiogenic effects in zebrafish embryos.

\begin{tabular}{llll}
\hline \multirow{2}{*}{ Compounds } & \multicolumn{4}{l}{ Anti-angiogenic phenotype } \\
\cline { 2 - 4 } & $\mathbf{1} \boldsymbol{\mu} \mathbf{M}$ & $\mathbf{2 . 5} \boldsymbol{\mu} \mathbf{M}$ & $\mathbf{1 0} \boldsymbol{\mu M}$ \\
\hline $\mathbf{4}$ & ++ & +++ & ++++ \\
$\mathbf{9}$ & + & ++ & ++ \\
$\mathbf{1 6}$ & $\bigcirc$ & $\bigcirc$ & ++ \\
$\mathbf{2 0}$ & $\bigcirc$ & 0 & ++ \\
$\mathbf{2 2}$ & $\bigcirc$ & 0 & ++ \\
$\mathbf{2 3}$ & 0 & 0 & ++ \\
$\mathbf{2 6}$ & ++ & ++ & ++ \\
$\mathbf{3 1}$ & 0 & + & ++ \\
$\mathbf{3 2}$ & ++ & +++ & ++++ \\
$\mathbf{3 5}$ & ++ & +++ & ++++ \\
$\mathbf{3 6}$ & ++ & +++ & ++++ \\
GA & ++ & Dead $^{\text {b }}$ & Dead \\
\hline
\end{tabular}

${ }^{\text {a }}$ The semiquantitative scale for angiogenic inhibitory rates, each group comprised 10 fishes, this experiment was repeated three times: $O$, inactive;,$++++>75 \%$ angiogenic inhibition; +++ , $50-75 \% ;++, 25-50 \% ;+,<25 \%$ suppression of angiogenesis as compared to the vehicle-treated $(0.05 \%$ DMSO) zebrafish embryos. ${ }^{b}>50 \%$ zebrafish embryos were dead when treated with the indicated concentration of compound.

Importantly, derivatives 4, 32, 35, 36 exhibited strong antiangiogenic activities inhibiting intersomitic blood vessels from the dorsal aorta of zebrafish in a concentration-dependent manner (Figures 1 and 2).

Figure 1. Effects on neovascularization in zebrafish embryos. The transgenic fli-1: enhanced GFP zebrafish embryos in embryo water $(0.2 \mathrm{~g} / \mathrm{L}$ of instant ocean salt in distilled water) incubated with $1 \mu \mathrm{M}$ of compounds at $6 \mathrm{~h}$ postfertilization (hpf) for $24 \mathrm{~h}$. Zebrafish embryos were imaged (Imager.Z1, magnification: left, 40×; right, 100×).

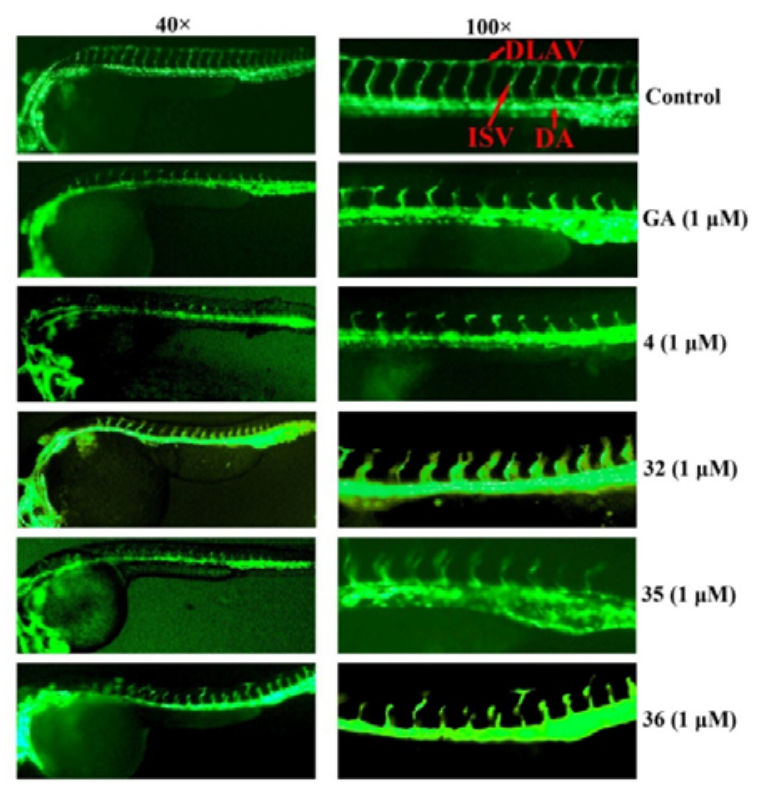


Figure 2. Effects of different concentrations of 4, 32, 35, 36 on neovascularization in zebrafish embryos (Imager.Z1, magnification: 100×).

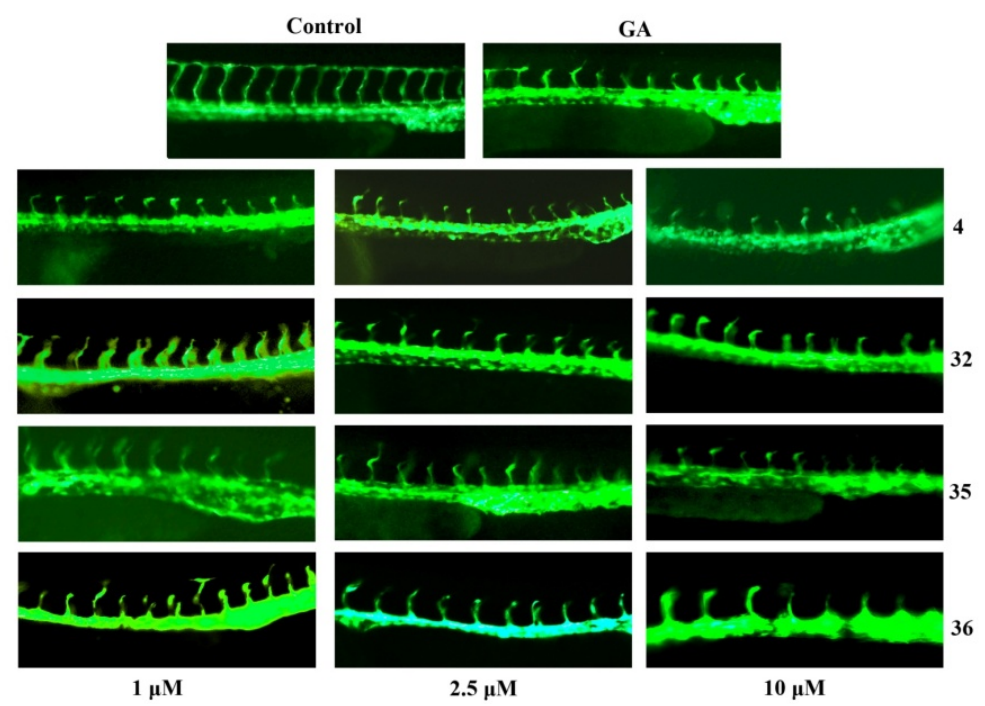

To investigate the toxicity of these four compounds, the heart rates and the mortality rates of zebrafish embryos were recorded (Tables 2 and 3). The heart rate of zebrafish in the control group was $117 \mathrm{beats} / \mathrm{min}$. At a concentration of $1 \mu \mathrm{M}$, treated with compounds 4, 32, 35, 36 respectively, the heart rates of zebrafish were slightly reduced to about 80 beats/min but the heart rate of zebrafish treated with GA decreased to 36 beats/min. Moreover, at $2.5 \mu \mathrm{M}$ and $10 \mu \mathrm{M} \mathrm{GA}, 73.3 \%$ and $100 \%$ of zebrafish embryos, respectively, were dead, whilst when treated with each of the four compounds at the same concentrations, the mortality rates were less than $20 \%$ and the heart rates were still about half of the control group. Therefore, we suggest that compounds 4, 32, 35, 36 were less toxic than GA in zebrafish screening model.

Table 2. The effects of $4,32,35,36$ on heart rates of zebrafish.

\begin{tabular}{llll}
\hline \multirow{2}{*}{ Compounds } & \multicolumn{3}{l}{ Heart rates of zebrafish(beats/min) } \\
\cline { 2 - 4 } & $\mathbf{1} \boldsymbol{\mu M}$ & $\mathbf{2 . 5} \boldsymbol{\mu M}$ & $\mathbf{1 0} \boldsymbol{\mu M}$ \\
\hline $\mathbf{4}$ & $84 \pm 3.22 * * *$ & $80 \pm 5.31$ & $54 \pm 4.00$ \\
$\mathbf{3 2}$ & $72 \pm 6.13 * *$ & $60 \pm 4.36$ & $54 \pm 3.68$ \\
$\mathbf{3 5}$ & $87 \pm 8.99 * *$ & $57 \pm 2.61$ & $45 \pm 4.95$ \\
$\mathbf{3 6}$ & $84 \pm 3.24 * * *$ & $60 \pm 5.2$ & $60 \pm 2.86$ \\
GA & $36 \pm 3.32$ & Dead $^{\mathbf{b}}$ & Dead \\
Control & 117 & & \\
\hline
\end{tabular}

${ }^{a}$ Data are mean of three experiments (each experiment comprised 10 fishes). ${ }^{b}>50 \%$ zebrafish embryos were dead when treated with the indicated concentration of compound. $* * p<0.01$, $* * * p<0.005$ compared with GA. 
Table 3. The effects of $4,32,35,36$ on the zebrafish mortality rate.

\begin{tabular}{llll}
\hline \multirow{2}{*}{ Compounds } & \multicolumn{3}{l}{ Mortality rates $(\%)^{\mathbf{a}}$} \\
\cline { 2 - 4 } & $\mathbf{1} \boldsymbol{\mu} \mathbf{M}$ & $\mathbf{2 . 5} \boldsymbol{\mu M}$ & $\mathbf{1 0} \boldsymbol{\mu M}$ \\
\hline $\mathbf{4}$ & 0 & $6.7 \pm 5.77 * *$ & $20 \pm 0.00 * * *$ \\
$\mathbf{3 2}$ & 0 & $6.7 \pm 5.77 * *$ & $16.7 \pm 5.77 * * *$ \\
$\mathbf{3 5}$ & $3.3 \pm 5.77 *$ & $10 \pm 0.07^{* * *}$ & $16.7 \pm 5.77 * * *$ \\
$\mathbf{3 6}$ & 0 & $3.3 \pm 5.77 * *$ & $16.7 \pm 5.77 * * *$ \\
$\mathbf{A}$ & $20 \pm 0.00$ & $73.3 \pm 5.77$ & 100 \\
Control & 0 & & \\
\hline
\end{tabular}

${ }^{\mathrm{a}}$ Data are mean of three experiments (each experiment comprised 10 fishes). ${ }^{*} p<0.05,{ }^{* *} p<0.01$, *** $p<0.005$ compared with GA.

\subsection{Effects on the HUVECs Migration}

The migration of ECs is an important step of angiogenesis [16,24]. The continuity of vascular ECs is the most important factor in preserving vessel wall function. Migration of ECs is essential to the recovery of this continuity after vascular ECs injury [24]. Since compounds 4, 32, 35 and 36 presented more antiangiogenic potency than GA, a would-healing migration assay was therefore applied to evaluate their ability to inhibit HUVECs migration [8]. As illustrated in Figure 3(I), the HUVECs migrated into the wound area actively (between the two white dash lines) under the compound-free condition (control).

Figure 3. Effects on the HUVECs migration. (I) HUVECs suspended in serum-free Dulbecco's Modified Eagle Medium (DMEM) containing compounds $(0.25$ or 0.5 or $1 \mu \mathrm{M})$ for $24 \mathrm{~h}$ were photographed under a phase contrast microscopy (Olympus CKX41, magnification: $50 \times$ ). Control was treated with serum-free DMEM which was consided as resulting in 100\%; (II) Migration rates of compounds on the HUVECs. Data represented the mean standard deviation (SD) from three independent experiments. *** $p<0.005$ compared with control.

(I)
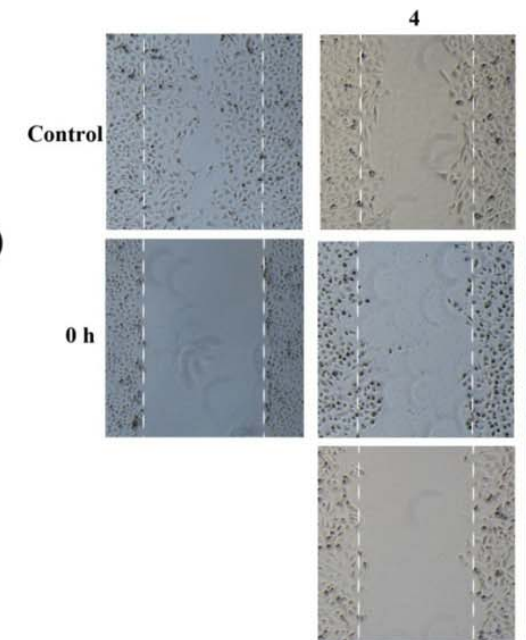

32

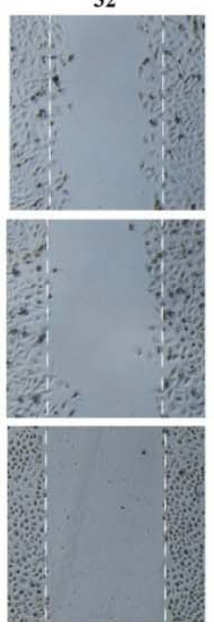

35

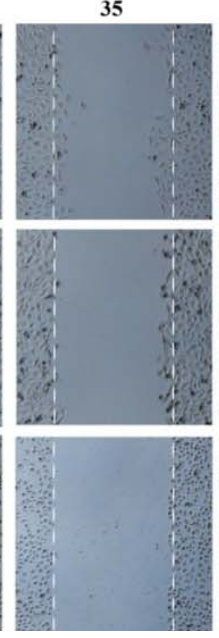

36

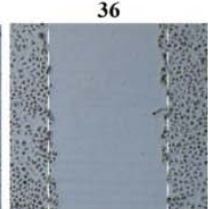

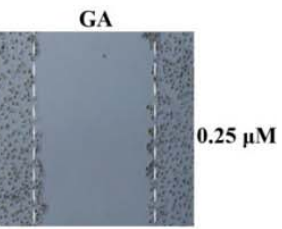

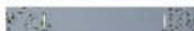

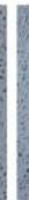
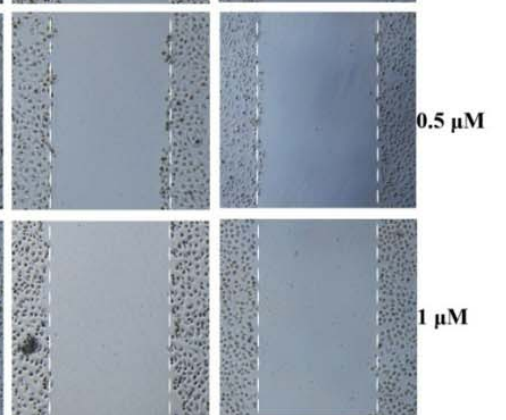

$1 \mu \mathrm{M}$ 
Figure 3. Cont.

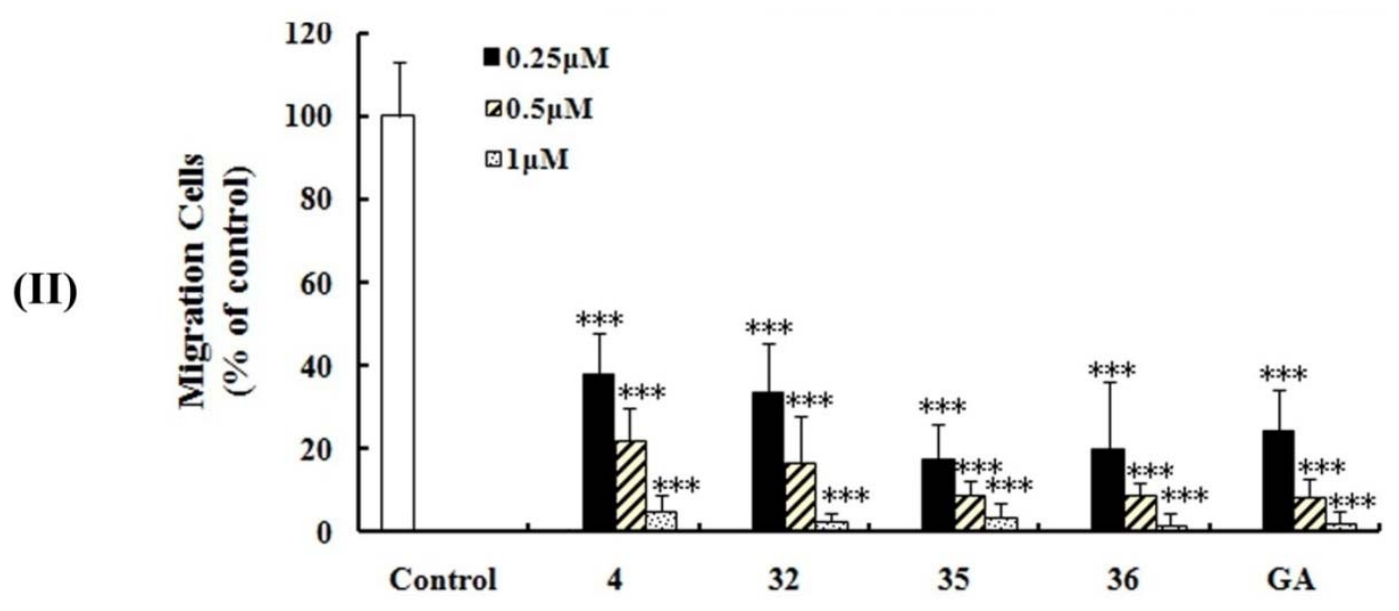

At a concentration of $0.25 \mu \mathrm{M}$, these four compounds showed significant differences compared with control, but only compounds 35, 36 manifested more potency compared with GA, and stronger inhibition than those of 4 and 32. At a concentration of $0.5 \mu \mathrm{M}$, derivatives 35,36 had similar potency to GA. At a concentration of $1 \mu \mathrm{M}$, compounds 35,36 were nearly equal to GA and the migratory rates were 3.6, 1.7 and 2.2\% respectively [Figure 3(II)]. The effects of these compounds were not due to cell death, because the HUVECs did not show any morphological changes include blebbing, cell shrinkage, nuclear fragmentation, chromatin condensation and chromosomal DNA fragmentation.

\subsection{Effects on the HUVECs Tube Formation}

In the later stages of angiogenesis, tube formation of ECs is also an important process [16]. Thus, a Matrigel tube formation assay was applied to assess the ability of HUVECs to form ECs vascular structures which is believed to be significant in new vessel formation [24].

In the control, HUVECs showed the highest mobility on Matrigel and formed an intact tubular network in $6 \mathrm{~h}$ (Figure 4I). In comparison with the control group, the inhibitory rates of samples treated with 4, 32, 35, 36 and GA at a concentration of $0.5 \mu \mathrm{M}$ were $43.5,39.1,37.0,56.5$ and $26.1 \%$, respectively. Among them, 36 had the strongest inhibitory activity with a 2-fold improvement in the inhibition of tube formation when compared with GA. Most significantly, at concentrations exceeding $1 \mu \mathrm{M}$, derivative 36 could completely inhibit tubular structures (Figure 4II), demonstrating that 36 was the most potent antiangiogenesis agent.

\subsection{Antiproliferative and Anticancer Activity}

Inhibiting the proliferation of ECs is another important strategy for antiangiogenesis [25]. Therefore, this experiment was designed to demonstrate the effects of the compounds on antiangiogenesis, HUVEC migration and tube formation. As the exposure time of these derivatives was $24 \mathrm{~h}$ in the migration assay and $6 \mathrm{~h}$ in the tube formation assay, the effect of the incubation for $24 \mathrm{~h}$ in the presence of these compounds on HUVECs proliferation was then tested. Cell viability was assessed by the MTT method [25]. We can see from Table 4 that these compounds had different antiproliferative activities. 
Figure 4. Effects on the HUVECs tube formation. (I) HUVECs $\left(1 \times 10^{4}\right.$ cells $)$ suspended in DMEM containing each compound $(0.5$ or 1 or $2 \mu \mathrm{M})$ were added to the Matrigel. Control was treated with DMEM alone. After incubation for $6 \mathrm{~h}$ at $37{ }^{\circ} \mathrm{C}$, capillary networks were photographed and quantified (Olympus CKX41, magnification: 100×); (II) Rates of the HUVECs tube formation. The number of intact tubes was counted in five randomly chosen regions and expressed as the percentage of the control. The results were expressed as mean $\pm \mathrm{SD} . * * p<0.01 ; * * * p<0.005$ compared with control.
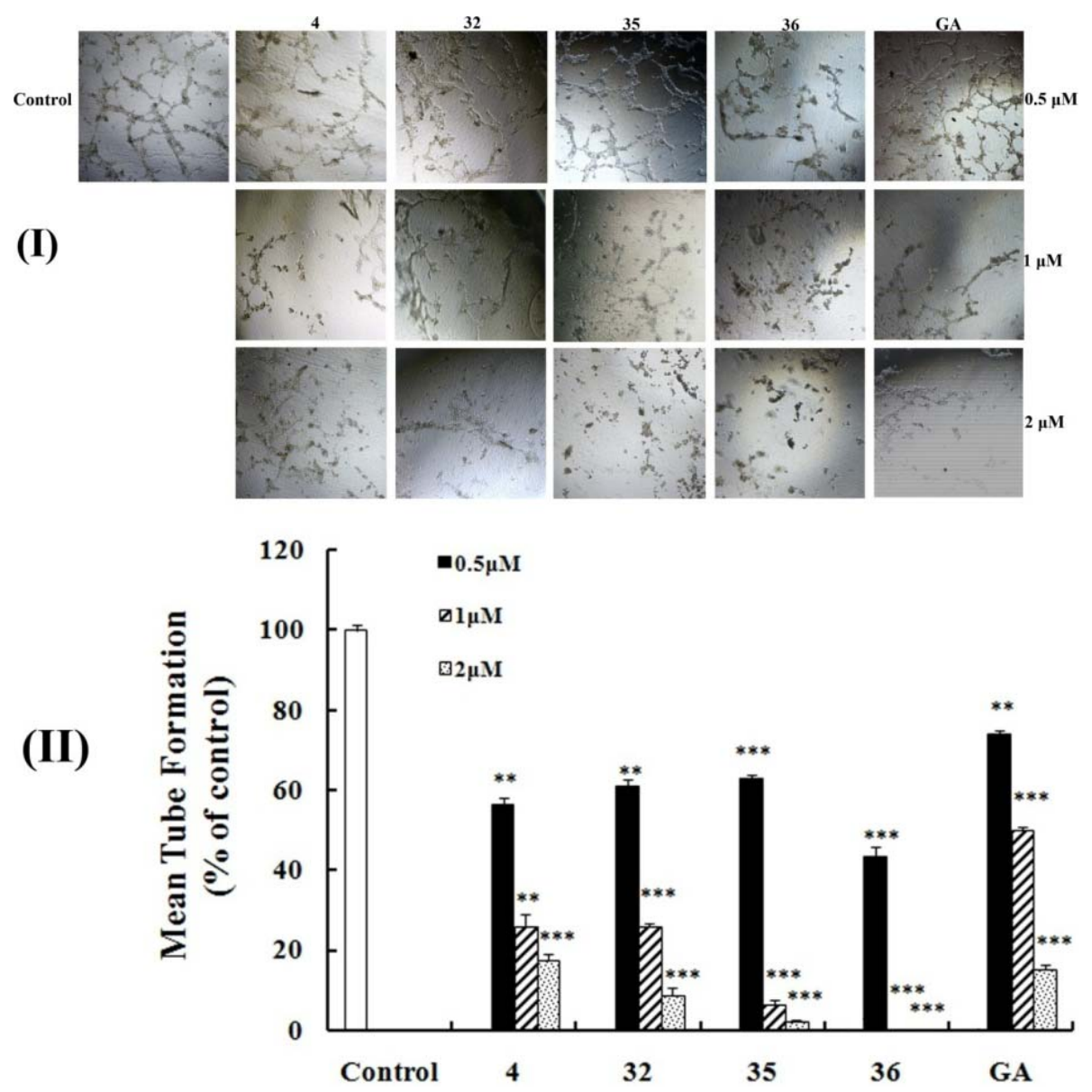

Table 4. Inhibition of cell proliferation by compounds 1-36 and GA.

\begin{tabular}{|c|c|c|c|c|c|c|c|}
\hline \multirow{2}{*}{ Compound } & \multicolumn{7}{|c|}{ Cell lines $(\mathrm{IC50}, \boldsymbol{\mu M})^{a}$} \\
\hline & A549 & HepG2 & HCT116 & K562 & HeLa & HUVEC & LO2 \\
\hline 1 & $43.50 \pm 3.92$ & $30.83 \pm 2.76$ & $25.53 \pm 1.79$ & $10.25 \pm 0.48$ & $32.89 \pm 1.69$ & $45.20 \pm 2.64$ & ND \\
\hline 2 & $49.15 \pm 5.16$ & $41.43 \pm 3.52$ & $45.27 \pm 4.20$ & $16.10 \pm 1.74$ & $57.00 \pm 0.62$ & $31.90 \pm 1.27$ & ND \\
\hline 3 & $38.03 \pm 3.10$ & $28.83 \pm 2.84$ & $18.68 \pm 0.97$ & $8.18 \pm 1.22$ & $13.07 \pm 0.77$ & $52.67 \pm 1.15$ & ND \\
\hline 4 & $0.95 \pm 0.09$ & $1.10 \pm 0.06$ & $0.48 \pm 0.04$ & $0.41 \pm 0.02^{*}$ & $1.34 \pm 0.04$ & $1.17 \pm 0.12$ & $0.83 \pm 0.03$ \\
\hline 5 & $5.53 \pm 0.40$ & $9.45 \pm 1.42$ & $5.47 \pm 0.24$ & $2.03 \pm 0.20$ & $6.37 \pm 0.11$ & $4.39 \pm 0.27$ & $4.03 \pm 0.34$ \\
\hline 6 & $19.70 \pm 2.62$ & $25.77 \pm 1.76$ & $14.53 \pm 1.22$ & $5.47 \pm 0.15$ & $33.30 \pm 1.83$ & $14.60 \pm 0.34$ & $>20$ \\
\hline 7 & $15.43 \pm 2.57$ & $10.77 \pm 1.10$ & $6.00 \pm 0.40$ & $2.50 \pm 0.12$ & $16.10 \pm 0.55$ & $10.90 \pm 0.72$ & 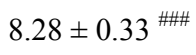 \\
\hline 8 & $>80$ & $>80$ & $66.40 \pm 1.10$ & $17.95 \pm 1.38$ & $>80$ & $77.50 \pm 3.65$ & ND \\
\hline 9 & $3.75 \pm 0.35$ & $5.16 \pm 0.55$ & $2.05 \pm 0.41$ & $1.14 \pm 0.03$ & $3.42 \pm 0.19$ & $4.27 \pm 0.25$ & $1.00 \pm 0.10$ \\
\hline 10 & $>80$ & $>80$ & $>80$ & $>80$ & $>80$ & $>80$ & ND \\
\hline 11 & $3.31 \pm 0.45$ & $3.64 \pm 0.53$ & $3.13 \pm 0.30$ & $2.09 \pm 0.19$ & $3.31 \pm 0.24$ & $3.48 \pm 0.18$ & $3.94 \pm 0.19$ \\
\hline
\end{tabular}


Table 4. Cont.

\begin{tabular}{|c|c|c|c|c|c|c|c|}
\hline \multirow{2}{*}{ Compound } & \multicolumn{7}{|c|}{ Cell lines $(\mathrm{IC50}, \mu \mathrm{M})^{\mathrm{a}}$} \\
\hline & A549 & HepG2 & HCT116 & K562 & HeLa & HUVEC & $\mathrm{LO2}$ \\
\hline 12 & $10.70 \pm 0.26$ & $7.80 \pm 0.11$ & $5.57 \pm 0.26$ & $1.79 \pm 0.08$ & $7.10 \pm 1.43$ & $7.58 \pm 1.36$ & $5.15 \pm 1.19^{\# \# \#}$ \\
\hline 13 & $66.75 \pm 4.59$ & $60.50 \pm 4.24$ & $17.47 \pm 1.59$ & $8.05 \pm 0.28$ & $>80$ & $27.67 \pm 2.77$ & ND \\
\hline 14 & $>80$ & $40.63 \pm 2.75$ & $34.80 \pm 1.84$ & $22.60 \pm 0.53$ & $>80$ & $41.95 \pm 2.76$ & 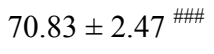 \\
\hline 15 & $32.95 \pm 1.50$ & $10.85 \pm 0.06$ & $6.80 \pm 0.78$ & $6.11 \pm 0.39$ & $62.57 \pm 3.12$ & $13.64 \pm 1.16$ & $14.83 \pm 1.19^{\# \# \#}$ \\
\hline 16 & $>80$ & $4.51 \pm 0.29$ & $5.08 \pm 0.77$ & $3.46 \pm 0.34$ & $8.98 \pm 0.58$ & $11.93 \pm 1.36$ & $5.25 \pm 0.51$ \\
\hline 17 & $>80$ & $61.90 \pm 2.69$ & $33.00 \pm 1.27$ & $27.00 \pm 1.41$ & $>80$ & $29.90 \pm 1.44$ & $72.83 \pm 2.84$ \#\#\# \\
\hline 18 & $66.15 \pm 1.65$ & $6.45 \pm 0.37$ & $2.45 \pm 0.15$ & $7.52 \pm 0.83$ & $>80$ & $10.37 \pm 1.08$ & $15.20 \pm 0.72$ \\
\hline 19 & $>80$ & $>80$ & $70.25 \pm 3.06$ & $>80$ & $>80$ & $68.00 \pm 4.00$ & $>80$ \\
\hline 20 & $31.20 \pm 2.29$ & $5.86 \pm 0.40$ & $7.90 \pm 0.14$ & $4.52 \pm 0.43$ & $24.33 \pm 2.13$ & $7.70 \pm 0.32$ & $9.92 \pm 0.52^{\# \# \#}$ \\
\hline 21 & $>80$ & $>80$ & $>80$ & $>80$ & $>80$ & $70.5 \pm 4.86$ & $>80$ \\
\hline 22 & $>80$ & $63.25 \pm 3.88$ & $36.90 \pm 0.64$ & $36.90 \pm 0.56$ & $>80$ & $51.30 \pm 1.10$ & $>80$ \\
\hline 23 & $73.50 \pm 3.40$ & $19.95 \pm 2.89$ & $15.93 \pm 1.46$ & $15.45 \pm 1.35$ & $61.65 \pm 5.86$ & $31.97 \pm 1.76$ & $31.70 \pm 1.94^{\# \# \#}$ \\
\hline 24 & $>80$ & $>80$ & $>80$ & $>80$ & $>80$ & $>80$ & $>80$ \\
\hline 25 & $>80$ & $>80$ & $>80$ & $>80$ & $>80$ & $>80$ & $>80$ \\
\hline 26 & $4.00 \pm 0.80$ & $1.72 \pm 0.12$ & $1.73 \pm 0.44$ & $0.77 \pm 0.03$ & $4.46 \pm 0.57$ & $2.98 \pm 0.10$ & $4.22 \pm 0.50$ \\
\hline 27 & $1.22 \pm 0.25$ & $0.69 \pm 0.08^{*}$ & $1.05 \pm 0.07$ & $0.52 \pm 0.02$ & $3.51 \pm 0.15$ & $0.50 \pm 0.03$ & $1.52 \pm 0.12^{\#}$ \\
\hline 28 & $0.91 \pm 0.03$ & $0.66 \pm 0.02^{*}$ & $0.83 \pm 0.04$ & $0.50 \pm 0.06$ & $1.70 \pm 0.09$ & $0.62 \pm 0.03$ & $1.61 \pm 0.15^{\#}$ \\
\hline 29 & $0.63 \pm 0.01^{* *}$ & $0.85 \pm 0.15$ & $1.63 \pm 0.15$ & $0.79 \pm 0.06$ & $1.45 \pm 0.07$ & $6.64 \pm 0.11$ & $4.28 \pm 0.33^{\# \# \#}$ \\
\hline 30 & $1.24 \pm 0.09$ & $1.72 \pm 0.03$ & $1.33 \pm 0.07$ & $0.44 \pm 0.02$ & $3.43 \pm 0.28$ & $1.03 \pm 0.07$ & $2.84 \pm 0.34^{\#}$ \\
\hline 31 & $61.60 \pm 1.73$ & $49.17 \pm 4.31$ & $18.85 \pm 1.34$ & $13.73 \pm 0.56$ & $57.93 \pm 2.60$ & $30.23 \pm 2.04$ & ND \\
\hline 32 & $0.74 \pm 0.04^{*}$ & $0.81 \pm 0.06$ & $0.45 \pm 0.01^{*}$ & $0.40 \pm 0.02$ & $1.08 \pm 0.10$ & $1.09 \pm 0.09$ & $1.70 \pm 0.48$ \\
\hline 33 & $1.30 \pm 0.08$ & $1.00 \pm 0.06$ & $1.20 \pm 0.09$ & $0.53 \pm 0.05$ & $4.23 \pm 0.39$ & $0.57 \pm 0.03$ & $1.75 \pm 0.09^{\#}$ \\
\hline 34 & $21.40 \pm 3.71$ & $8.65 \pm 0.46$ & $7.74 \pm 1.43$ & $>20$ & $>80$ & $5.63 \pm 0.20$ & $7.30 \pm 1.20^{\#}$ \\
\hline 35 & $0.50 \pm 0.05^{* *}$ & $0.27 \pm 0.05^{* *}$ & $0.40 \pm 0.02^{* *}$ & $0.26 \pm 0.01^{* *}$ & $0.49 \pm 0.02^{* * *}$ & $0.20 \pm 0.01^{* * *}$ & $1.17 \pm 0.41$ \\
\hline 36 & $1.29 \pm 0.14$ & $1.85 \pm 0.08$ & $0.56 \pm 0.01$ & $0.28 \pm 0.03^{*}$ & $4.96 \pm 0.88$ & $2.45 \pm 0.09$ & $1.62 \pm 0.08^{\#}$ \\
\hline GA & $0.94 \pm 0.03$ & $0.84 \pm 0.04$ & $0.59 \pm 0.03$ & $0.49 \pm 0.03$ & $1.14 \pm 0.06$ & $0.27 \pm 0.01$ & $0.89 \pm 0.08$ \\
\hline
\end{tabular}

ND, not determined. ${ }^{a}$ Data are the mean of three experiments. ${ }^{*} p<0.05 ;{ }^{* *} p<0.01 ;{ }^{* * *} p<0.005$ compared with GA. ${ }^{\#} p<0.05$;

\# $p<0.01 ; \ldots$

Among them, the $\mathrm{IC}_{50}$ value for the parent compound (GA) was $0.94 \mu \mathrm{M}$ in A549 cell line, $0.84 \mu \mathrm{M}$ in HepG2 cell line, $0.59 \mu \mathrm{M}$ in HCT116 cell line, $0.49 \mu \mathrm{M}$ in K562 cell line, $1.14 \mu \mathrm{M}$ in HeLa cell line and $0.27 \mu \mathrm{M}$ in HUVEC cell line, respectively. Compound $\mathbf{3 6}$ showed similar cytotoxicity against the same cell lines, $1.29 \mu \mathrm{M}$ in A549 cell line, $1.85 \mu \mathrm{M}$ in HepG2 cell line, $0.56 \mu \mathrm{M}$ in HCT116 cell line, $0.28 \mu \mathrm{M}$ in $\mathrm{K} 562$ cell line, $4.96 \mu \mathrm{M}$ in HeLa cell line and $2.45 \mu \mathrm{M}$ in HUVEC cell line. Importantly, compound 36 showed relatively lower toxicities to LO2 cell line than GA.

\subsection{Structure-Activity Relationship}

As a result of zebrafish embryos assay, wound-healing assay, tube formation assay and MTT assay, we found that compared to the unsubstituted GA, introduction of electron-withdrawing groups (EWG; e.g., nitro for 1, 5, 8, 14; halogenations including chlorine, bromine and fluorine atoms for $\mathbf{2}$, $17,19,24$; cyano for 12 ; carbonyl for $5,11,15,16,20,23$ ) and electron-donating groups on the phenyl ring (EDG; e.g., methoxyl for 3, 13, 22, 31; 2-methoxyethyl for 18; ethyl for 21; 
2,4,4-trimethylpentan-2-yl for 25) failed to improve their antiangiogenic potencies in contrast to GA. The acetamido group at the para position of the phenyl ring (para-acetamido for 4 and 35) improved the antiangiogenic activity. A heterocyclic ring substituent (thiazole for 32) showed more potency compared with GA. These properties may contribute to the basic groups which can improve the solubility of the compounds in acidic media [22]. It has been reported that epoxidation of the carboncarbon double bond at C-32/33, C-37/38 could improve antiangiogenic activity [21]. Therefore, we modified the carbon-carbon double bond on the structure of $\mathbf{3 5}$ to produce derivative $\mathbf{3 6}$. We found that it indeed improved antiangiogenic activity.

\section{Experimental}

\subsection{Chemistry}

All commercial chemicals and solvents were reagent grade and were used without further treatment unless otherwise noted. Chemistry reagents of analytical grade were purchased from Chengdu Changzheng Chemical Factory, Sichuan, China. Analytical thin-layer chromatography was performed on $0.20 \mathrm{~mm}$ Silica Gel $60 \mathrm{~F}_{254}$ plates (Qingdao Ocean Chemical Factory, Shandong, China). Nuclear magnetic resonance spectra (NMR) were recorded at $400 \mathrm{MHz}$ on a Varian model Gemini 400 spectrometer (Varian, Palo Alto, CA, USA) and peaks are reported in parts per million. Mass spectra (MS) were measured by a Q-TOF Premier mass spectrometer (Micromass, Manchester, UK).

General procedure for the synthesis of gambogates, gambogthioesters and gambogamides 1-35. A mixture of gambogic acid $(0.18 \mathrm{mmol}), \mathrm{R}-\mathrm{OH}$ or R-SH or $\mathrm{R}-\mathrm{NH}_{2}(0.20 \mathrm{mmol}), \mathrm{DMAP}(0.10 \mathrm{mmol})$ and EDCI $(0.30 \mathrm{mmol})$ in $\mathrm{CH}_{2} \mathrm{Cl}_{2}(10 \mathrm{~mL})$ was stirred at $25^{\circ} \mathrm{C}$ overnight. The solution was washed by hydrochloric acid solution $(2 \times 10 \mathrm{~mL})$ and water $(2 \times 10 \mathrm{~mL})$. The combined organic layer was dried and concentrated to yield the crude product, which was purified by silica gel column chromatography.

4-Methyl-3-nitrophenyl gambogate (1) Yield 70.6\%; HPLC: 98.6\%; yellow oil; ${ }^{1} \mathrm{H}-\mathrm{NMR}\left(\mathrm{CDCl}_{3}\right)$ : $\delta 12.81(\mathrm{~s}, 1 \mathrm{H}), 7.54(\mathrm{q}, J=2.8 \mathrm{~Hz}, 1 \mathrm{H}), 7.32(\mathrm{~m}, 1 \mathrm{H}), 6.64(\mathrm{~m}, 2 \mathrm{H}), 6.41(\mathrm{~m}, 1 \mathrm{H}), 5.45(\mathrm{~m}, 1 \mathrm{H}), 5.05(\mathrm{~m}$, 2H), $3.48(\mathrm{t}, J=5.6 \mathrm{~Hz}, 1 \mathrm{H}), 3.32(\mathrm{~m}, 1 \mathrm{H}), 3.16(\mathrm{~d}, J=9.2 \mathrm{~Hz}, 1 \mathrm{H}), 3.03-2.89(\mathrm{~m}, 2 \mathrm{H}), 2.56(\mathrm{t}$, $J=7.2 \mathrm{~Hz}, 1 \mathrm{H}), 2.35(\mathrm{~m}, 1 \mathrm{H}), 2.04(\mathrm{~m}, 2 \mathrm{H}), 1.73(\mathrm{~m}, 6 \mathrm{H}), 1.66(\mathrm{~s}, 3 \mathrm{H}), 1.62(\mathrm{~d}, J=4.4 \mathrm{~Hz}, 3 \mathrm{H}), 1.58$ $(\mathrm{s}, 3 \mathrm{H}), 1.55(\mathrm{~s}, 3 \mathrm{H}), 1.47-1.38(\mathrm{~m}, 3 \mathrm{H}), 1.35(\mathrm{~s}, 1 \mathrm{H}), 1.30(\mathrm{~d}, J=6.4 \mathrm{~Hz}, 3 \mathrm{H}), 1.26(\mathrm{~s}, 2 \mathrm{H})$; MS (ESI, $\mathrm{m} / \mathrm{z}): 819.29[\mathrm{M}-\mathrm{H}]^{-}$.

6-Bromo-2,3-difluorophenyl gambogate (2) Yield 67\%; HPLC: 98.2\%; yellow oil; ${ }^{1} \mathrm{H}-\mathrm{NMR}\left(\mathrm{CDCl}_{3}\right)$ : $\delta 12.81(\mathrm{~s}, 1 \mathrm{H}), 7.54(\mathrm{q}, J=2.8 \mathrm{~Hz}, 1 \mathrm{H}), 7.32(\mathrm{~m}, 1 \mathrm{H}), 6.64(\mathrm{~m}, 2 \mathrm{H}), 6.41(\mathrm{~m}, 1 \mathrm{H}), 5.45(\mathrm{~m}, 1 \mathrm{H}), 5.05$ $(\mathrm{m}, 2 \mathrm{H}), 3.48(\mathrm{t}, J=5.6 \mathrm{~Hz}, 1 \mathrm{H}), 3.32(\mathrm{~m}, 1 \mathrm{H}), 3.16(\mathrm{~d}, J=9.2 \mathrm{~Hz}, 1 \mathrm{H}), 3.03-2.89(\mathrm{~m}, 2 \mathrm{H}), 2.56(\mathrm{t}$, $J=7.2 \mathrm{~Hz}, 1 \mathrm{H}), 2.35(\mathrm{~m}, 1 \mathrm{H}), 2.04(\mathrm{~m}, 2 \mathrm{H}), 1.73(\mathrm{~m}, 6 \mathrm{H}), 1.66(\mathrm{~s}, 3 \mathrm{H}), 1.62(\mathrm{~d}, J=4.4 \mathrm{~Hz}, 3 \mathrm{H}), 1.58$ $(\mathrm{s}, 3 \mathrm{H}), 1.55(\mathrm{~s}, 3 \mathrm{H}), 1.47-1.38(\mathrm{~m}, 3 \mathrm{H}), 1.35(\mathrm{~s}, 1 \mathrm{H}), 1.30(\mathrm{~d}, J=6.4 \mathrm{~Hz}, 3 \mathrm{H}), 1.26(\mathrm{~s}, 2 \mathrm{H})$; MS (ESI, $m / z): 819.29[\mathrm{M}-\mathrm{H}]^{-}$.

4-Allyl-2-methoxyphenyl gambogate (3). Yield 75\%; HPLC: 98.5\%; brown oil; ${ }^{1} \mathrm{H}-\mathrm{NMR}\left(\mathrm{CDCl}_{3}\right): \delta$ $12.82(\mathrm{~s}, 1 \mathrm{H}), 7.48(\mathrm{~d}, J=7.2 \mathrm{~Hz}, 1 \mathrm{H}), 6.70(\mathrm{~m}, 4 \mathrm{H}), 6.35(\mathrm{~s}, 1 \mathrm{H}), 5.94(\mathrm{~m}, 1 \mathrm{H}), 5.44(\mathrm{~m}, 1 \mathrm{H}), 5.08$ (m, 4H), $3.67(\mathrm{~d}, J=3.6 \mathrm{~Hz}, 3 \mathrm{H}), 3.44(\mathrm{~s}, 1 \mathrm{H}), 3.35$ (m, 3H), 3.19 (d, $J=14.4 \mathrm{~Hz}, 1 \mathrm{H}), 2.95$ (m, 2H), 2.53 
(t, $J=8.4 \mathrm{~Hz}, 1 \mathrm{H}), 2.3(\mathrm{dd}, J=13.6 \mathrm{~Hz}, J=4.8 \mathrm{~Hz}, 1 \mathrm{H}), 2.06(\mathrm{~m}, 2 \mathrm{H}), 1.74(\mathrm{~m}, 6 \mathrm{H}), 1.65(\mathrm{~m}, 6 \mathrm{H}), 1.55$ (s, 6H), $1.40(\mathrm{~m}, 3 \mathrm{H}), 1.31(\mathrm{~m}, 6 \mathrm{H})$; MS (ESI, $m / z): 774.51[\mathrm{M}-\mathrm{H}]^{-}$.

4-Acetamidephenyl gambogate (4). Yield 72\%; HPLC: 99.1\%; yellow oil; ${ }^{1} \mathrm{H}-\mathrm{NMR}\left(\mathrm{CDCl}_{3}\right): \delta 12.83$ (s, 1H), $7.52(\mathrm{~d}, J=7.2 \mathrm{~Hz}, 1 \mathrm{H}), 7.45(\mathrm{~d}, J=7.6 \mathrm{~Hz}, 2 \mathrm{H}), 7.12(\mathrm{br}, 1 \mathrm{H}), 6.83$ (d, $J=7.6 \mathrm{~Hz}, 2 \mathrm{H})$, $6.64(\mathrm{~m}, 1 \mathrm{H}), 6.33(\mathrm{~m}, 1 \mathrm{H}), 5.42(\mathrm{t}, J=11.2 \mathrm{~Hz}, 1 \mathrm{H}), 5.05(\mathrm{~m}, 2 \mathrm{H}), 3.47(\mathrm{~s}, 1 \mathrm{H}), 3.34(\mathrm{~m}, 1 \mathrm{H}), 3.16$ $(\mathrm{d}, J=11.2 \mathrm{~Hz}, 1 \mathrm{H}), 3.06(\mathrm{~m}, 1 \mathrm{H}), 2.93(\mathrm{~m}, 1 \mathrm{H}), 2.54(\mathrm{~d}, J=9.6 \mathrm{~Hz}, 1 \mathrm{H}), 2.32$ (dd, $J=12.8 \mathrm{~Hz}$, $J=3.2 \mathrm{~Hz}, 1 \mathrm{H}), 2.17$ (s, 3H), $2.05(\mathrm{~m}, 2 \mathrm{H}), 1.87$ (d, $J=4 \mathrm{~Hz}, 3 \mathrm{H}), 1.73(\mathrm{~m}, 6 \mathrm{H}), 1.63$ (m, 6H), 1.55 $(\mathrm{s}, 3 \mathrm{H}), 1.41(\mathrm{~m}, 3 \mathrm{H}), 1.32(\mathrm{~m}, 3 \mathrm{H})$; MS (ESI, $m / z): 762.42[\mathrm{M}+\mathrm{H}]^{+}$.

2-Nitro-4-ethanonephenyl gambogate (5) Yield 63\%; HPLC: 98.8\%; Yellow oil; ${ }^{1} \mathrm{H}$ NMR $\left(\mathrm{CDCl}_{3}\right): \delta$ $12.83(\mathrm{~s}, 1 \mathrm{H}), 8.59(\mathrm{~m}, 1 \mathrm{H}), 8.18(\mathrm{~m}, 1 \mathrm{H}), 7.55(\mathrm{t}, J=6.8 \mathrm{~Hz}, 1 \mathrm{H}), 7.46(\mathrm{dd}, J=8.4 \mathrm{~Hz}, J=2 \mathrm{~Hz}, 1 \mathrm{H})$, $6.65(\mathrm{~m}, 1 \mathrm{H}), 6.48(\mathrm{~m}, 1 \mathrm{H}), 5.45(\mathrm{~m}, 1 \mathrm{H}), 5.06(\mathrm{~m}, 2 \mathrm{H}), 3.52(\mathrm{~m}, 1 \mathrm{H}), 3.33(\mathrm{~m}, 1 \mathrm{H}), 3.18(\mathrm{~m}, 1 \mathrm{H})$, $2.93(\mathrm{~m}, 2 \mathrm{H}), 2.67(\mathrm{t}, 3 \mathrm{H}), 2.55(\mathrm{~m}, 1 \mathrm{H}), 2.35(\mathrm{~m}, 1 \mathrm{H}), 2.08(\mathrm{~m}, 2 \mathrm{H}), 1.74(\mathrm{~m}, 6 \mathrm{H}), 1.66(\mathrm{~m}, 9 \mathrm{H}), 1.51$ $(\mathrm{s}, 3 \mathrm{H}), 1.39(\mathrm{~m}, 3 \mathrm{H}), 1.26(\mathrm{~m}, 6 \mathrm{H})$; MS (ESI, $m / z: 792.33)[\mathrm{M}+\mathrm{H}]^{+}$.

Coumarin-3-gambogate (6) Yield 52\%; HPLC: 99.1\%; buff-colored oil; ${ }^{1} \mathrm{H}-\mathrm{NMR}\left(\mathrm{CDCl}_{3}\right): \delta 12.90$ (s, $1 \mathrm{H}), 7.55(\mathrm{~d}, J=6.8 \mathrm{~Hz}), 7.50(\mathrm{~m}, 2 \mathrm{H}), 7.31(\mathrm{~m}, 3 \mathrm{H}), 6.65(\mathrm{~d}, J=10.4 \mathrm{~Hz}, 1 \mathrm{H}), 6.44(\mathrm{~m}, 1 \mathrm{H}), 5.43(\mathrm{~m}$, $1 \mathrm{H}), 5.04(\mathrm{~m}, 2 \mathrm{H}), 3.48(\mathrm{~m}, 1 \mathrm{H}), 3.37(\mathrm{~m}, 1 \mathrm{H}), 3.12(\mathrm{~m}, 2 \mathrm{H}), 2.87(\mathrm{~m}, 1 \mathrm{H}), 2.55(\mathrm{~d}, J=9.2 \mathrm{~Hz}, 1 \mathrm{H})$, $2.32(\mathrm{dd}, J=13.2 \mathrm{~Hz}, J=4.4 \mathrm{~Hz}, 1 \mathrm{H}), 2.05(\mathrm{~m}, 2 \mathrm{H}), 1.78(\mathrm{~m}, 6 \mathrm{H}), 1.63(\mathrm{~m}, 6 \mathrm{H}), 1.57$ (m, 3H), 1.39 $(\mathrm{m}, 6 \mathrm{H}), 1.25(\mathrm{~m}, 6 \mathrm{H})$; MS (ESI, $m / z): 773.79[\mathrm{M}+\mathrm{H}]^{+}$.

Coumarin-7-gambogate (7) Yield 66\%; HPLC: 99.2\%; buff-colored oil; ${ }^{1} \mathrm{H}-\mathrm{NMR}\left(\mathrm{CDCl}_{3}\right): \delta 12.81$ (s, 1H), $7.66(\mathrm{~m}, 1 \mathrm{H}), 7.54(\mathrm{dd}, J=6.8 \mathrm{~Hz}, J=2 \mathrm{~Hz}, 1 \mathrm{H}), 7.44(\mathrm{~m}, 1 \mathrm{H}), 6.97(\mathrm{~d}, J=2 \mathrm{~Hz}, 1 \mathrm{H}), 6.83$ (m, $1 \mathrm{H}), 6.32(\mathrm{~d}, J=10 \mathrm{~Hz}, 1 \mathrm{H}), 6.37(\mathrm{~m}, 2 \mathrm{H}), 5.43(\mathrm{~m}, 1 \mathrm{H}), 5.04(\mathrm{br}, 2 \mathrm{H}), 3.49(\mathrm{~s}, 1 \mathrm{H}), 3.34(\mathrm{~m}, 1 \mathrm{H})$, $3.18(\mathrm{~m}, 1 \mathrm{H}), 3.06(\mathrm{~m}, 1 \mathrm{H}), 2.95(\mathrm{~m}, 1 \mathrm{H}), 2.55(\mathrm{~d}, J=8.8 \mathrm{~Hz}, 1 \mathrm{H}), 2.33(\mathrm{dd}, J=13.6 \mathrm{~Hz}, J=4.4 \mathrm{~Hz}$, 1H), $2.02(\mathrm{~m}, 2 \mathrm{H}), 1.75(\mathrm{~m}, 6 \mathrm{H}), 1.65(\mathrm{~m}, 6 \mathrm{H}), 1.55(\mathrm{~m}, 3 \mathrm{H}), 1.36(\mathrm{~m}, 6 \mathrm{H}), 1.26(\mathrm{~m}, 6 \mathrm{H})$; MS (ESI, $m / z): 773.79[\mathrm{M}+\mathrm{H}]^{+}$.

3-Nitrophenyl gambogate (8) Yield 87\%; HPLC: 99.1\%; yellow oil; ${ }^{1} \mathrm{H}-\mathrm{NMR}\left(\mathrm{CDCl}_{3}\right): \delta 12.79$ (s, $1 \mathrm{H}), 8.06(\mathrm{~d}, J=7.6 \mathrm{~Hz}, 1 \mathrm{H}), 7.84(\mathrm{~s}, 1 \mathrm{H}), 7.52(\mathrm{~m}, 2 \mathrm{H}), 6.62(\mathrm{~d}, J=10 \mathrm{~Hz}, 1 \mathrm{H}), 6.36(\mathrm{t}, J=6.8 \mathrm{~Hz}$, $1 \mathrm{H}), 5.39$ (d, $J=10 \mathrm{~Hz}, 1 \mathrm{H}), 5.03(\mathrm{br}, 2 \mathrm{H}), 3.49$ (t, $J=5.2 \mathrm{~Hz}, 1 \mathrm{H}), 3.33$ (dd, $J=14.4 \mathrm{~Hz}, J=8 \mathrm{~Hz}$, $1 \mathrm{H}), 3.17(\mathrm{~m}, 1 \mathrm{H}), 3.06(\mathrm{dd}, J=16.8 \mathrm{~Hz}, J=8 \mathrm{~Hz}, 1 \mathrm{H}), 2.96(\mathrm{dd}, J=16.8 \mathrm{~Hz}, J=5.2 \mathrm{~Hz}, 1 \mathrm{H}), 2.56$ $(\mathrm{d}, J=8.8 \mathrm{~Hz}, 1 \mathrm{H}), 2.33(\mathrm{dd}, J=13.2 \mathrm{~Hz}, J=4.4 \mathrm{~Hz}, 1 \mathrm{H}), 2.01(\mathrm{~m}, 2 \mathrm{H}), 1.73(\mathrm{~s}, 3 \mathrm{H}), 1.72(\mathrm{~s}, 3 \mathrm{H}), 1.64$ $(\mathrm{s}, 3 \mathrm{H}), 1.62(\mathrm{~s}, 3 \mathrm{H}), 1.56(\mathrm{~s}, 3 \mathrm{H}), 1.37(\mathrm{~m}, 6 \mathrm{H}), 1.30(\mathrm{~s}, 3 \mathrm{H}), 1.25(\mathrm{~s}, 3 \mathrm{H})$; MS (ESI, m/z): $750.55[\mathrm{M}+\mathrm{H}]^{+}$.

3-Chloro-N-(4-phenylgambogate)propanamide (9) Yield 39\%; HPLC: 99.4\%; yellow oil; ${ }^{1} \mathrm{H}-\mathrm{NMR}$ $\left(\mathrm{CDCl}_{3}\right): \delta 12.83(\mathrm{~s}, 1 \mathrm{H}), 7.52(\mathrm{~d}, J=7.2 \mathrm{~Hz}, 1 \mathrm{H}), 7.44(\mathrm{dd}, J=8.8 \mathrm{~Hz}, J=2 \mathrm{~Hz}, 2 \mathrm{H}), 7.37(\mathrm{~d}$, $J=11.2 \mathrm{~Hz}, 1 \mathrm{H}), 6.83(\mathrm{~d}, J=8.4 \mathrm{~Hz}, 2 \mathrm{H}), 6.63(\mathrm{~m}, 1 \mathrm{H}), 6.35(\mathrm{~m}, 1 \mathrm{H}), 5.43(\mathrm{~m}, 1 \mathrm{H}), 5.05(\mathrm{~m}, 2 \mathrm{H})$, $3.87(\mathrm{t}, J=6.4 \mathrm{~Hz}, 2 \mathrm{H}), 3.47(\mathrm{~m}, 1 \mathrm{H}), 3.34(\mathrm{~m}, 1 \mathrm{H}), 3.17-3.04(\mathrm{~m}, 2 \mathrm{H}), 2.90(\mathrm{~m}, 1 \mathrm{H}), 2.78(\mathrm{t}$, $J=6 \mathrm{~Hz}, 2 \mathrm{H}), 2.54(\mathrm{~d}, J=9.2 \mathrm{~Hz}, 1 \mathrm{H}), 2.31(\mathrm{dd}, J=13.2 \mathrm{~Hz}, J=4.4 \mathrm{~Hz}, 1 \mathrm{H}), 2.03(\mathrm{~m}, 2 \mathrm{H}), 1.87$ (s, $3 \mathrm{H}), 1.75(\mathrm{~m}, 6 \mathrm{H}), 1.64(\mathrm{~m}, 6 \mathrm{H}), 1.55(\mathrm{~s}, 3 \mathrm{H}), 1.38(\mathrm{~s}, 3 \mathrm{H}), 1.34(\mathrm{~s}, 3 \mathrm{H}), 1.30(\mathrm{~s}, 3 \mathrm{H})$; MS (ESI, $m / z)$ : $810.53[\mathrm{M}+\mathrm{H}]^{+}$. 
Geraniol gambogate (10) Yield 39\%; HPLC: 98.5\%; yellow oil; ${ }^{1} \mathrm{H}-\mathrm{NMR}\left(\mathrm{CDCl}_{3}\right): \delta 12.79(\mathrm{~s}, 1 \mathrm{H})$, $7.52(\mathrm{t}, J=6.8 \mathrm{~Hz}, 1 \mathrm{H}), 6.68(\mathrm{~m}, 1 \mathrm{H}), 6.32(\mathrm{t}, J=4 \mathrm{~Hz}, 1 \mathrm{H}), 5.45(\mathrm{~d}, J=9.2 \mathrm{~Hz}, 1 \mathrm{H}), 5.32$ $(\mathrm{t}, J=6.8 \mathrm{~Hz}, 1 \mathrm{H}), 5.15(\mathrm{~m}, 1 \mathrm{H}), 5.06(\mathrm{~m}, 2 \mathrm{H}), 4.56(\mathrm{~m}, 2 \mathrm{H}), 3.50(\mathrm{~m}, 1 \mathrm{H}), 3.31(\mathrm{~m}, 2 \mathrm{H}), 3.15-2.95$ $(\mathrm{m}, 1 \mathrm{H}), 2.64(\mathrm{~d}, J=7.6 \mathrm{~Hz}, 2 \mathrm{H}), 2.52(\mathrm{dd}, J=9.6 \mathrm{~Hz}, J=4.0 \mathrm{~Hz}, 1 \mathrm{H}), 2.33(\mathrm{~m}, 1 \mathrm{H}), 2.12-2.01(\mathrm{~m}$, $6 \mathrm{H}), 1.76(\mathrm{~m}, 6 \mathrm{H}), 1.64(\mathrm{~m}, 12 \mathrm{H}), 1.61(\mathrm{~m}, 6 \mathrm{H}), 1.58(\mathrm{~s}, 3 \mathrm{H}), 1.43(\mathrm{~s}, 3 \mathrm{H}), 1.38(\mathrm{~s}, 3 \mathrm{H}), 1.29(\mathrm{~s}, 3 \mathrm{H})$; MS (ESI, $m / z): 787.79[\mathrm{M}+\mathrm{Na}]^{+}$.

3-Ethanonephenyl gambogate (11) Yield 91\%; HPLC: 99.1\%; yellow oil; ${ }^{1} \mathrm{H}-\mathrm{NMR}\left(\mathrm{CDCl}_{3}\right)$ : $\delta 12.87$ (s, 1H), $7.78(\mathrm{~d}, J=5.2 \mathrm{~Hz}, 1 \mathrm{H}), 7.52(\mathrm{~m}, 2 \mathrm{H}), 7.42(\mathrm{~m}, 1 \mathrm{H}), 7.08(\mathrm{~m}, 1 \mathrm{H}), 6.63(\mathrm{~m}, 1 \mathrm{H}), 6.40(\mathrm{~m}$, $1 \mathrm{H}), 5.41(\mathrm{~m}, 1 \mathrm{H}), 5.03(\mathrm{br}, 2 \mathrm{H}), 3.47(\mathrm{~s}, 1 \mathrm{H}), 3.35(\mathrm{~m}, 1 \mathrm{H}), 3.17(\mathrm{~m}, 1 \mathrm{H}), 3.07(\mathrm{dd}, J=17.2 \mathrm{~Hz}$, $J=8.4 \mathrm{~Hz}, 1 \mathrm{H}), 2.92(\mathrm{~m}, 1 \mathrm{H}), 2.60(\mathrm{~s}, 3 \mathrm{H}), 2.56(\mathrm{~m}, 1 \mathrm{H}), 2.31(\mathrm{dd}, J=13.6 \mathrm{~Hz}, J=4.4 \mathrm{~Hz}, 1 \mathrm{H}), 2.02$ $(\mathrm{m}, 2 \mathrm{H}), 1.90(\mathrm{~d}, J=4.4 \mathrm{~Hz}, 3 \mathrm{H}), 1.78(\mathrm{~m}, 7 \mathrm{H}), 1.64(\mathrm{~m}, 7 \mathrm{H}), 1.55(\mathrm{~m}, 3 \mathrm{H}), 1.39(\mathrm{~m}, 4 \mathrm{H}), 1.30$ (s, $3 \mathrm{H})$; MS (ESI, $m / z): 745.62[\mathrm{M}-\mathrm{H}]^{-}$.

3-Cyanophenyl gambogate (12) Yield 86\%; HPLC: 99.3\%; brown oil; ${ }^{1} \mathrm{H}-\mathrm{NMR}\left(\mathrm{CDCl}_{3}\right)$ : $\delta 12.83$ (s, $1 \mathrm{H}), 7.54(\mathrm{~d}, J=5.2 \mathrm{~Hz}, 1 \mathrm{H}), 7.44(\mathrm{~m}, 2 \mathrm{H}), 7.23(\mathrm{~m}, 1 \mathrm{H}), 7.14(\mathrm{~m}, 1 \mathrm{H}), 6.40(\mathrm{dd}, J=10.4 \mathrm{~Hz}, J=6.0 \mathrm{~Hz}$, $1 \mathrm{H}), 6.43-6.32(\mathrm{~m}, 1 \mathrm{H}), 5.44(\mathrm{dd}, J=12.4 \mathrm{~Hz}, J=10.4 \mathrm{~Hz}, 1 \mathrm{H}), 5.04(\mathrm{~m}, 2 \mathrm{H}), 3.48(\mathrm{~m}, 1 \mathrm{H}), 3.34$ (m, $1 \mathrm{H}), 3.13(\mathrm{~m}, 1 \mathrm{H}), 3.04(\mathrm{~m}, 1 \mathrm{H}), 2.97-2.86(\mathrm{~m}, 1 \mathrm{H}), 2.55(\mathrm{~d}, J=9.2 \mathrm{~Hz}, 1 \mathrm{H}), 2.32(\mathrm{~m}, 1 \mathrm{H}), 2.01(\mathrm{~m}$, 2H), $1.89(\mathrm{~d}, J=8.0 \mathrm{~Hz}, 3 \mathrm{H}), 1.74(\mathrm{~d}, J=4.0 \mathrm{~Hz}, 4 \mathrm{H}), 1.72(\mathrm{~d}, J=3.2 \mathrm{~Hz}, 3 \mathrm{H}), 1.64(\mathrm{~m}, 6 \mathrm{H}), 1.54(\mathrm{~d}$, $J=4.4 \mathrm{~Hz}, 3 \mathrm{H}), 1.36(\mathrm{~m}, 3 \mathrm{H}), 1.30(\mathrm{~s}, 3 \mathrm{H}), 1.28(\mathrm{~s}, 2 \mathrm{H})$; MS (ESI, $m / z): 752.45\left[\mathrm{M}+\mathrm{Na}^{+}\right.$.

4-Methoxyphenyl gambogate (13) Yield 92\%; HPLC: 99.5\%; brown oil; ${ }^{1} \mathrm{H}-\mathrm{NMR}\left(\mathrm{CDCl}_{3}\right)$ : $\delta 12.86$ (s, $1 \mathrm{H}), 7.53(\mathrm{~d}, J=6.4 \mathrm{~Hz}, 1 \mathrm{H}), 6.80(\mathrm{~m}, 4 \mathrm{H}), 6.66(\mathrm{~d}, J=10.0 \mathrm{~Hz}, 1 \mathrm{H}), 6.32(\mathrm{t}, J=6.4 \mathrm{~Hz}, 1 \mathrm{H}), 5.42$ $(\mathrm{d}, J=10.4 \mathrm{~Hz}, 1 \mathrm{H}), 5.05(\mathrm{~m}, 2 \mathrm{H}), 3.79(\mathrm{~s}, 3 \mathrm{H}), 3.48(\mathrm{~m}, 1 \mathrm{H}), 3.34(\mathrm{~m}, 1 \mathrm{H}), 3.18(\mathrm{~m}, 1 \mathrm{H}), 3.08(\mathrm{~m}$, 1H), $2.94(\mathrm{~m}, 1 \mathrm{H}), 2.55(\mathrm{~d}, J=9.2 \mathrm{~Hz}, 1 \mathrm{H}), 2.32(\mathrm{~m}, 1 \mathrm{H}), 2.05(\mathrm{~m}, 2 \mathrm{H}), 1.88(\mathrm{~s}, 3 \mathrm{H}), 1.78(\mathrm{~m}, 6 \mathrm{H})$, $1.63(\mathrm{~m}, 6 \mathrm{H}), 1.58(\mathrm{~s}, 3 \mathrm{H}), 1.40(\mathrm{~s}, 3 \mathrm{H}), 1.31(\mathrm{~m}, 6 \mathrm{H})$; MS (ESI, $m / z): 733.77[\mathrm{M}-\mathrm{H}]^{-}$.

3-Methyl-2-nitrophenyl gambogate (14) Yield 78\%; HPLC: 99.1\%; yellow powder; ${ }^{1} \mathrm{H}-\mathrm{NMR}\left(\mathrm{CDCl}_{3}\right)$ : $\delta 12.86(\mathrm{~s}, 1 \mathrm{H}), 7.53(\mathrm{~d}, J=7.2 \mathrm{~Hz}, 1 \mathrm{H}), 7.34(\mathrm{t}, J=8.0 \mathrm{~Hz}, 1 \mathrm{H}), 7.10(\mathrm{~d}, J=8.0 \mathrm{~Hz}, 1 \mathrm{H}), 6.90(8.4 \mathrm{~Hz}$, $1 \mathrm{H}), 6.60(\mathrm{~d}, J=10.0 \mathrm{~Hz}, 1 \mathrm{H}), 6.41(\mathrm{t}, J=6.0 \mathrm{~Hz}, 1 \mathrm{H}), 5.38(\mathrm{~d}, J=10.0 \mathrm{~Hz}, 1 \mathrm{H}), 5.04(\mathrm{~m}, 2 \mathrm{H}), 3.47$ $(\mathrm{m}, 1 \mathrm{H}), 3.33(\mathrm{dd}, J=10.4 \mathrm{~Hz}, J=8.0 \mathrm{~Hz}, 1 \mathrm{H}), 3.16(\mathrm{dd}, J=14.4 \mathrm{~Hz}, J=4.8 \mathrm{~Hz}, 1 \mathrm{H}), 2.99$ (m, $1 \mathrm{H}), 2.88$ (m, 1H), $2.53(\mathrm{~d}, J=9.2 \mathrm{~Hz}, 1 \mathrm{H}), 2.32(\mathrm{~s}, 3 \mathrm{H}), 2.29(\mathrm{~d}, J=4.8 \mathrm{~Hz}, 1 \mathrm{H}), 2.01(\mathrm{~m}, 2 \mathrm{H}), 1.83(\mathrm{~s}, 3 \mathrm{H}), 1.74$ (s, 3H), $1.71(\mathrm{~s}, 3 \mathrm{H}), 1.65(\mathrm{~s}, 3 \mathrm{H}), 1.62(\mathrm{~s}, 3 \mathrm{H}), 1.55(\mathrm{~s}, 3 \mathrm{H}), 1.38(\mathrm{~s}, 3 \mathrm{H}), 1.29(\mathrm{~s}, 3 \mathrm{H}), 1.25$ (s, 3H); MS $(\mathrm{ESI}, \mathrm{m} / z): 733.40[\mathrm{M}+\mathrm{H}]^{+}$.

3-Formylphenyl gambogate (15) Yield 87\%; HPLC: 98.3\%; brown oil; ${ }^{1} \mathrm{H}-\mathrm{NMR}\left(\mathrm{CDCl}_{3}\right): \delta 12.84$ (s, 1H), $9.98(\mathrm{~s}, 1 \mathrm{H}), 7.72(\mathrm{~d}, J=7.6 \mathrm{~Hz}, 1 \mathrm{H}), 7.53(\mathrm{~d}, J=6.8 \mathrm{~Hz}, 1 \mathrm{H}), 7.48$ (t, $J=8.0 \mathrm{~Hz}, 1 \mathrm{H}), 7.42$ (s, $1 \mathrm{H}), 7.15(\mathrm{~d}, J=8.0 \mathrm{~Hz}, 1 \mathrm{H}), 6.62(\mathrm{~d}, J=10.0 \mathrm{~Hz}, 1 \mathrm{H}), 6.37(\mathrm{t}, J=6.8 \mathrm{~Hz}, 1 \mathrm{H}), 5.39(\mathrm{~d}, J=10.0 \mathrm{~Hz}$, $1 \mathrm{H}), 5.04(\mathrm{~s}, 2 \mathrm{H}), 3.50(\mathrm{t}, J=4.8 \mathrm{~Hz}, 1 \mathrm{H}), 3.33(\mathrm{~m}, 1 \mathrm{H}), 3.14(\mathrm{~m}, 1 \mathrm{H}), 3.08(\mathrm{t}, J=8.0 \mathrm{~Hz}, 1 \mathrm{H}), 2.94(\mathrm{dd}$, $J=16.8 \mathrm{~Hz}, J=4.4 \mathrm{~Hz}, 1 \mathrm{H}), 2.55(\mathrm{~d}, J=9.6 \mathrm{~Hz}, 1 \mathrm{H}), 2.32(\mathrm{dd}, J=13.6 \mathrm{~Hz}, J=4.8 \mathrm{~Hz}, 1 \mathrm{H}), 2.01(\mathrm{~m}$, 2H), $1.90(\mathrm{~s}, 3 \mathrm{H}), 1.73(\mathrm{~s}, 3 \mathrm{H}), 1.72(\mathrm{~s}, 3 \mathrm{H}), 1.65(\mathrm{~s}, 3 \mathrm{H}), 1.62(\mathrm{~s}, 3 \mathrm{H}), 1.55(\mathrm{~s}, 3 \mathrm{H}), 1.35(\mathrm{~s}, 3 \mathrm{H}), 1.31$ (s, $3 \mathrm{H}), 1.26(\mathrm{~s}, 3 \mathrm{H})$; MS (ESI, $m / z): 733.40[\mathrm{M}+\mathrm{H}]^{+}$. 
4-(2-Bromoacetyl)phenyl gambogate (16) Yield 73\%; HPLC: 98.9\%; yellow oil; ${ }^{1} \mathrm{H}-\mathrm{NMR}\left(\mathrm{CDCl}_{3}\right): \delta$ $12.83(\mathrm{~s}, 1 \mathrm{H}), 7.93(\mathrm{~d}, J=8.4 \mathrm{~Hz}, 2 \mathrm{H}), 7.53(\mathrm{~d}, J=7.2 \mathrm{~Hz}, 1 \mathrm{H}), 7.02(\mathrm{~d}, J=8.4 \mathrm{~Hz}, 2 \mathrm{H}), 6.62$ $(\mathrm{d}, J=10.0 \mathrm{~Hz}, 1 \mathrm{H}), 6.36(\mathrm{t}, J=6.4 \mathrm{~Hz}, 1 \mathrm{H}), 5.40(\mathrm{~d}, J=10.0 \mathrm{~Hz}, 1 \mathrm{H}), 5.04(\mathrm{~m}, 2 \mathrm{H}), 4.69(\mathrm{~s}, 2 \mathrm{H}), 3.48$ (m, 1H), 3. $31(\mathrm{dd}, J=14.8 \mathrm{~Hz}, J=7.6 \mathrm{~Hz}, 1 \mathrm{H}), 3.16(\mathrm{~m}, 1 \mathrm{H}), 3.06(\mathrm{~m}, 1 \mathrm{H}), 2.97(\mathrm{~m}, 1 \mathrm{H}), 2.55(\mathrm{~d}$, $J=9.6 \mathrm{~Hz}, 1 \mathrm{H}), 2.33(\mathrm{dd}, J=13.2 \mathrm{~Hz}, J=4.4 \mathrm{~Hz}, 1 \mathrm{H}), 2.01(\mathrm{~m}, 2 \mathrm{H}), 1.88$ (s, 3H), 1.73 (s, 3H), 1.72 (s, $3 \mathrm{H}), 1.65(\mathrm{~s}, 3 \mathrm{H}), 1.62(\mathrm{~s}, 3 \mathrm{H}), 1.56(\mathrm{~s}, 3 \mathrm{H}), 1.36(\mathrm{~m}, 4 \mathrm{H}), 1.27(\mathrm{~m}, 5 \mathrm{H})$; MS (ESI, $m / z): 825.78[\mathrm{M}+\mathrm{H}]^{+}$.

2-Bromophenyl gambogate (17) Yield 88\%; HPLC: 98.5\%; brown oil; ${ }^{1} \mathrm{H}-\mathrm{NMR}\left(\mathrm{CDCl}_{3}\right)$ : $\delta 12.86$ (s, $1 \mathrm{H}), 7.52(\mathrm{~m}, 2 \mathrm{H}), 7.27(\mathrm{~m}, 1 \mathrm{H}), 7.05(\mathrm{~m}, 1 \mathrm{H}), 6.94(\mathrm{dd}, J=8.0 \mathrm{~Hz}, J=1.2 \mathrm{~Hz}, 1 \mathrm{H}), 6.64(\mathrm{~d}, J=10.0 \mathrm{~Hz}$, $1 \mathrm{H}), 6.46(\mathrm{t}, J=6.4 \mathrm{~Hz}, 1 \mathrm{H}), 5.41(\mathrm{~d}, J=10.0 \mathrm{~Hz}, 1 \mathrm{H}), 5.05(\mathrm{br}, 2 \mathrm{H}), 3.46(\mathrm{~m}, 1 \mathrm{H}), 3.35$ (dd, $J=14.4 \mathrm{~Hz}, J=8.0 \mathrm{~Hz}, 1 \mathrm{H}), 3.20(\mathrm{~m}, 1 \mathrm{H}), 3.06(\mathrm{dd}, J=17.6 \mathrm{~Hz}, J=7.2 \mathrm{~Hz}, 1 \mathrm{H}), 2.96(\mathrm{~m}, 1 \mathrm{H}), 2.54(\mathrm{~d}$, $J=9.2 \mathrm{~Hz}, 1 \mathrm{H}), 2.31(\mathrm{dd}, J=13.6 \mathrm{~Hz}, J=4.4 \mathrm{~Hz}, 1 \mathrm{H}), 2.04(\mathrm{~m}, 2 \mathrm{H}), 1.95$ (s, 3H), $1.75(\mathrm{~s}, 3 \mathrm{H}), 1.73$ (s, $3 \mathrm{H}), 1.65(\mathrm{~s}, 3 \mathrm{H}), 1.63(\mathrm{~s}, 3 \mathrm{H}), 1.55(\mathrm{~s}, 3 \mathrm{H}), 1.40(\mathrm{~m}, 5 \mathrm{H}), 1.28(\mathrm{~m}, 4 \mathrm{H})$; MS (ESI, $m / z): 783.42[\mathrm{M}+\mathrm{H}]^{+}$.

4-(2-Methoxyethyl)phenyl gambogate (18). Yield 82\%; HPLC: 99.0\%; brown powder; ${ }^{1} \mathrm{H}-\mathrm{NMR}$ $\left(\mathrm{CDCl}_{3}\right): \delta 12.84(\mathrm{~s}, 1 \mathrm{H}), 7.51(\mathrm{~d}, J=7.2 \mathrm{~Hz}, 1 \mathrm{H}), 7.15(\mathrm{~d}, J=8.0 \mathrm{~Hz}, 2 \mathrm{H}), 6.78(\mathrm{~d}, J=8.4 \mathrm{~Hz}, 2 \mathrm{H})$, $6.65(\mathrm{~d}, J=10.0 \mathrm{~Hz}, 1 \mathrm{H}), 6.31(\mathrm{t}, J=6.4 \mathrm{~Hz}, 1 \mathrm{H}), 5.41(\mathrm{~d}, J=10.0 \mathrm{~Hz}, 1 \mathrm{H}), 5.05(\mathrm{br}, 2 \mathrm{H}), 3.56$ (t, $J=7.2 \mathrm{~Hz}, 2 \mathrm{H}), 3.46(\mathrm{~m}, 1 \mathrm{H}), 3.35(\mathrm{~s}, 3 \mathrm{H}), 3.31(\mathrm{~m}, 1 \mathrm{H}), 3.18(\mathrm{~m}, 1 \mathrm{H}), 3.03(\mathrm{~m}, 1 \mathrm{H}), 2.94(\mathrm{~m}, 1 \mathrm{H}), 2.84$ (t, $7.2 \mathrm{~Hz}, 2 \mathrm{H}), 2.53(\mathrm{~d}, J=9.2 \mathrm{~Hz}, 1 \mathrm{H}), 2.31(\mathrm{dd}, J=13.6 \mathrm{~Hz}, J=4.8 \mathrm{~Hz}, 1 \mathrm{H}), 2.03(\mathrm{~m}, 2 \mathrm{H}), 1.86$ (s, $3 \mathrm{H}), 1.73(\mathrm{~s}, 3 \mathrm{H}), 1.71(\mathrm{~s}, 3 \mathrm{H}), 1.65(\mathrm{~s}, 3 \mathrm{H}), 1.62(\mathrm{~s}, 3 \mathrm{H}), 1.55(\mathrm{~s}, 3 \mathrm{H}), 1.38(\mathrm{~m}, 5 \mathrm{H}), 1.29(\mathrm{~m}, 4 \mathrm{H})$; MS $(\mathrm{ESI}, \mathrm{m} / z): 785.78[\mathrm{M}+\mathrm{Na}]^{+}$.

4-Bromophenyl gambogate (19) Yield 92\%; HPLC: 99.2\%; yellow oil; ${ }^{1} \mathrm{H}-\mathrm{NMR}\left(\mathrm{CDCl}_{3}\right): \delta 12.83$ (s, $1 \mathrm{H}), 7.52(\mathrm{~d}, J=6.8 \mathrm{~Hz}, 1 \mathrm{H}), 7,41(\mathrm{~d}, J=8.4 \mathrm{~Hz}, 2 \mathrm{H}), 6.76(\mathrm{~d}, J=8.8 \mathrm{~Hz}, 2 \mathrm{H}), 6.63(\mathrm{~d}, J=10.4 \mathrm{~Hz}$, $1 \mathrm{H}), 6.29(\mathrm{t}, J=6.8 \mathrm{~Hz}, 1 \mathrm{H}), 5.41(\mathrm{~d}, J=10.0 \mathrm{~Hz}, 1 \mathrm{H}), 5.04(\mathrm{~s}, 2 \mathrm{H}), 3.47$ (t, $J=5.2 \mathrm{~Hz}, 1 \mathrm{H}), 3.31(\mathrm{dd}$, $J=14.0 \mathrm{~Hz}, 1 \mathrm{H}), 3.17(\mathrm{~m}, 1 \mathrm{H}), 3.05(\mathrm{dd}, J=17.2 \mathrm{~Hz}, J=7.6 \mathrm{~Hz}, 1 \mathrm{H}), 2.97(\mathrm{~m}, 1 \mathrm{H}), 2.54(\mathrm{~d}, J=9.6 \mathrm{~Hz}$, $1 \mathrm{H}), 2.31(\mathrm{dd}, J=13.6 \mathrm{~Hz}, J=4.4 \mathrm{~Hz}, 1 \mathrm{H}), 2.03(\mathrm{~m}, 2 \mathrm{H}), 1.86(\mathrm{~s}, 3 \mathrm{H}), 1.76(\mathrm{~s}, 3 \mathrm{H}), 1.73(\mathrm{~s}, 3 \mathrm{H}), 1.65$ $(\mathrm{s}, 3 \mathrm{H}), 1.62(\mathrm{~s}, 3 \mathrm{H}), 1.57(\mathrm{~s}, 3 \mathrm{H}), 1.37(\mathrm{~m}, 5 \mathrm{H}), 1.25(\mathrm{~m}, 4 \mathrm{H})$; MS (ESI, $m / z): 805.62[\mathrm{M}+\mathrm{Na}]^{+}$.

4-Formylphenyl gambogate (20) Yield 89\%; HPLC: 99.5\%; brown oil; ${ }^{1} \mathrm{H}-\mathrm{NMR}\left(\mathrm{CDCl}_{3}\right)$ : $\delta 12.82$ (s, 1H), 9.96 (s, 1H), 7.85 (d, $J=8.4 \mathrm{~Hz}, 2 \mathrm{H}), 7.52$ (d, $J=6.8 \mathrm{~Hz}, 1 \mathrm{H}), 7.05(\mathrm{~d}, J=8.4 \mathrm{~Hz}, 2 \mathrm{H}), 6.61(\mathrm{~d}$, $J=10.0 \mathrm{~Hz}, 1 \mathrm{H}), 6.33(\mathrm{t}, J=6.8 \mathrm{~Hz}, 1 \mathrm{H}), 5.39(\mathrm{~d}, J=10.4 \mathrm{~Hz}, 1 \mathrm{H}), 5.03(\mathrm{br}, 2 \mathrm{H}), 3.48(\mathrm{t}, J=5.6 \mathrm{~Hz}$, $1 \mathrm{H}), 3.31(\mathrm{dd}, J=14.8 \mathrm{~Hz}, J=8.0 \mathrm{~Hz}, 1 \mathrm{H}), 3.17(\mathrm{~m}, 1 \mathrm{H}), 3.06(\mathrm{~m}, 1 \mathrm{H}), 2.96(\mathrm{dd}, J=17.2 \mathrm{~Hz}$, $J=5.2 \mathrm{~Hz}, 1 \mathrm{H}), 2.54(\mathrm{~d}, J=9.2 \mathrm{~Hz}, 1 \mathrm{H}), 2.32(\mathrm{dd}, J=13.2 \mathrm{~Hz}, J=4.4 \mathrm{~Hz}, 1 \mathrm{H}), 2.01(\mathrm{~m}, 2 \mathrm{H}), 1.88$ (s, $3 \mathrm{H}), 1.72(\mathrm{~s}, 3 \mathrm{H}), 1.71(\mathrm{~s}, 3 \mathrm{H}), 1.64(\mathrm{~s}, 3 \mathrm{H}), 1.61(\mathrm{~s}, 3 \mathrm{H}), 1.57$ (s, 3H), 1.39 (m, 5H), 1.29 (m, 4H); MS (ESI, $m / z): 755.61[\mathrm{M}+\mathrm{Na}]^{+}$.

4-Ethylphenyl gambogate (21) Yield 87\%; HPLC: 99.3\%; yellow oil; ${ }^{1} \mathrm{H}-\mathrm{NMR}\left(\mathrm{CDCl}_{3}\right): \delta 12.83(\mathrm{~s}, 1 \mathrm{H})$, $7.51(\mathrm{~d}, J=6.8 \mathrm{~Hz}, 1 \mathrm{H}), 7.12(\mathrm{~d}, J=8.0 \mathrm{~Hz}, 2 \mathrm{H}), 6.77(\mathrm{~d}, J=8.0 \mathrm{~Hz}, 2 \mathrm{H}), 6.66(\mathrm{~d}, J=10.0 \mathrm{~Hz}, 1 \mathrm{H}), 6.31$ $(\mathrm{t}, J=6.8 \mathrm{~Hz}, 1 \mathrm{H}), 5.41(\mathrm{~d}, J=10.4 \mathrm{~Hz}, 1 \mathrm{H}), 5.04(\mathrm{br}, 2 \mathrm{H}), 3.46(\mathrm{t}, J=5.6 \mathrm{~Hz}, 1 \mathrm{H}), 3.32$ (dd, $J=14.4 \mathrm{~Hz}$, $J=8.0 \mathrm{~Hz}, 1 \mathrm{H}), 3.17(\mathrm{~m}, 1 \mathrm{H}), 3.06(\mathrm{dd}, J=16.8 \mathrm{~Hz}, J=7.6 \mathrm{~Hz}, 1 \mathrm{H}), 2.93(\mathrm{dd}, 16.4 \mathrm{~Hz}, J=5.6 \mathrm{~Hz}$, 1H), $2.61(\mathrm{~m}, 2 \mathrm{H}), 2.54(\mathrm{~d}, J=8.8 \mathrm{~Hz}, 1 \mathrm{H}), 2.31(\mathrm{dd}, J=13.2 \mathrm{~Hz}, J=4.4 \mathrm{~Hz}, 1 \mathrm{H}), 2.02(\mathrm{~m}, 2 \mathrm{H}), 1.87$ 
$(\mathrm{s}, 3 \mathrm{H}), 1.73(\mathrm{~s}, 3 \mathrm{H}), 1.72(\mathrm{~s}, 3 \mathrm{H}), 1.65(\mathrm{~s}, 3 \mathrm{H}), 1.62(\mathrm{~s}, 3 \mathrm{H}), 1.55(\mathrm{~s}, 3 \mathrm{H}), 1.41(\mathrm{~m}, 5 \mathrm{H}), 1.30(\mathrm{~m}, 4 \mathrm{H})$, $1.20(\mathrm{t}, J=7.6 \mathrm{~Hz}, 3 \mathrm{H})$; MS (ESI, $m / z): 755.56[\mathrm{M}+\mathrm{Na}]^{+}$.

2-Bromo-4-methoxyphenyl gambogate (22) Yield 73\%; HPLC: 98.7\%; brown oil; ${ }^{1} \mathrm{H}-\mathrm{NMR}\left(\mathrm{CDCl}_{3}\right)$ : $\delta$ $12.85(\mathrm{~s}, 1 \mathrm{H}), 7.52(\mathrm{~d}, J=6.8 \mathrm{~Hz}, 1 \mathrm{H}), 7.04(\mathrm{~d}, J=2.8 \mathrm{~Hz}, 1 \mathrm{H}), 6.80(\mathrm{~m}, 2 \mathrm{H}), 6.63(\mathrm{~d}, J=10.0 \mathrm{~Hz}$, $1 \mathrm{H}), 6.44(\mathrm{t}, J=6.8 \mathrm{~Hz}, 1 \mathrm{H}), 5.41(\mathrm{~d}, J=10.0 \mathrm{~Hz}, 1 \mathrm{H}), 5.05(\mathrm{br}, 2 \mathrm{H}), 3.75(\mathrm{~s}, 3 \mathrm{H}), 3.46(\mathrm{~m}, 1 \mathrm{H}), 3.33$ $(\mathrm{m}, 1 \mathrm{H}), 3.20(\mathrm{~m}, 1 \mathrm{H}), 3.03(\mathrm{~m}, 1 \mathrm{H}), 2.95(\mathrm{~m}, 1 \mathrm{H}), 2.53(\mathrm{~d}, J=9.2 \mathrm{~Hz}, 1 \mathrm{H}), 2.30(\mathrm{dd}, J=13.6 \mathrm{~Hz}$, $J=4.8 \mathrm{~Hz}, 1 \mathrm{H}), 2.01(\mathrm{~m}, 2 \mathrm{H}), 1.93(\mathrm{~s}, 3 \mathrm{H}), 1.74(\mathrm{~s}, 3 \mathrm{H}), 1.72(\mathrm{~s}, 3 \mathrm{H}), 1.65(\mathrm{~s}, 3 \mathrm{H}), 1.63(\mathrm{~s}, 3 \mathrm{H}), 1.55$ $(\mathrm{s}, 3 \mathrm{H}), 1.40(\mathrm{~m}, 5 \mathrm{H}), 1.29(\mathrm{~m}, 4 \mathrm{H})$; MS (ESI, $m / z): 835.56[\mathrm{M}+\mathrm{Na}]^{+}$.

4-Chloro-2-formylphenyl gambogate (23) Yield 69\%; HPLC: 99.6\%; brown oil; ${ }^{1} \mathrm{H}-\mathrm{NMR}\left(\mathrm{CDCl}_{3}\right): \delta$ $12.81(\mathrm{~s}, 1 \mathrm{H}), 9.95(\mathrm{~s}, 1 \mathrm{H}), 7.78(\mathrm{~d}, J=2.4 \mathrm{~Hz}, 1 \mathrm{H}), 7.52(\mathrm{~m}, 2 \mathrm{H}), 6.98(\mathrm{~d}, J=8.4 \mathrm{~Hz}, 1 \mathrm{H}), 6.57(\mathrm{~d}$, $J=10.0 \mathrm{~Hz}, 1 \mathrm{H}), 6.38(\mathrm{t}, J=6.4 \mathrm{~Hz}, 1 \mathrm{H}), 5.39$ (d, $J=10.0 \mathrm{~Hz}, 1 \mathrm{H}), 5.03(\mathrm{br}, 2 \mathrm{H}), 3.48(\mathrm{~m}, 1 \mathrm{H}), 3.31$ $(\mathrm{dd}, J=14.4 \mathrm{~Hz}, J=8.0 \mathrm{~Hz}, 1 \mathrm{H}), 3.17(\mathrm{~m}, 1 \mathrm{H}), 3.01(\mathrm{~m}, 2 \mathrm{H}), 2.54(\mathrm{~d}, J=8.8 \mathrm{~Hz}, 1 \mathrm{H}), 2.32(\mathrm{dd}$, $J=13.2 \mathrm{~Hz}, J=4.4 \mathrm{~Hz}, 1 \mathrm{H}), 2.02(\mathrm{~m}, 2 \mathrm{H}), 1.98$ (s, 3H), 1.78 (s, 3H), 1.71 (s, 3H), 1.64 (s, 3H), 1.62 $(\mathrm{s}, 3 \mathrm{H}), 1.54(\mathrm{~s}, 3 \mathrm{H}), 1.38(\mathrm{~m}, 4 \mathrm{H}), 1.30(\mathrm{~m}, 5 \mathrm{H})$; MS (ESI, $m / z): 767.25[\mathrm{M}+\mathrm{Na}]^{+}$.

4-Bromo-2,3-difluorophenyl gambogate (24) Yield 72\%; HPLC: 99.3\%; brown oil; ${ }^{1} \mathrm{H}-\mathrm{NMR}\left(\mathrm{CDCl}_{3}\right)$ : $\delta 12.80(\mathrm{~s}, 1 \mathrm{H}), 7.53(\mathrm{~d}, J=7.2 \mathrm{~Hz}, 1 \mathrm{H}), 7.27(\mathrm{~m}, 1 \mathrm{H}), 6.69(\mathrm{~m}, 1 \mathrm{H}), 6.62(\mathrm{~d}, J=10.4 \mathrm{~Hz}, 1 \mathrm{H}), 6.40$ $(\mathrm{t}, J=6.8 \mathrm{~Hz}, 1 \mathrm{H}), 5.42(\mathrm{~d}, J=10.0 \mathrm{~Hz}, 1 \mathrm{H}), 5.04(\mathrm{~m}, 2 \mathrm{H}), 3.48(\mathrm{~m}, 1 \mathrm{H}), 3.31(\mathrm{dd}, J=14.4 \mathrm{~Hz}, J=8 \mathrm{~Hz}$, $1 \mathrm{H}), 3.16(\mathrm{dd}, J=14.4 \mathrm{~Hz}, J=4.8 \mathrm{~Hz}, 1 \mathrm{H}), 2.95(\mathrm{~m}, 2 \mathrm{H}), 2.54(\mathrm{~d}, J=9.2 \mathrm{~Hz}, 1 \mathrm{H}), 2.32$ (dd, $J=13.2 \mathrm{~Hz}$, $J=4.4 \mathrm{~Hz}, 1 \mathrm{H}), 2.02(\mathrm{~m}, 2 \mathrm{H}), 1.90$ (s, 3H), 1.76 (s, 3H), 1.71 (s, 3H), 1.65 (s, 3H), 1.62 (s, 3H), 1.57 $(\mathrm{s}, 3 \mathrm{H}), 1.38(\mathrm{~m}, 5 \mathrm{H}), 1.27(\mathrm{~m}, 4 \mathrm{H}) ; \mathrm{MS}(\mathrm{ESI}, \mathrm{m} / z): 841.48[\mathrm{M}+\mathrm{Na}]^{+}$.

4-(2,4,4-Trimethylpentan-2-yl)phenyl gambogate (25) Yield 81\%; HPLC: 99.2\%; yellow powder; ${ }^{1} \mathrm{H}-\mathrm{NMR}\left(\mathrm{CDCl}_{3}\right): \delta 12.84(\mathrm{~s}, 1 \mathrm{H}), 7.54(\mathrm{~d}, J=6.8 \mathrm{~Hz}, 1 \mathrm{H}), 7.28(\mathrm{~d}, J=8.8 \mathrm{~Hz}, 2 \mathrm{H}), 6.77(\mathrm{~d}, J=8.8 \mathrm{~Hz}$, $2 \mathrm{H}), 6.66(\mathrm{dd}, J=10.0 \mathrm{~Hz}, J=3.6 \mathrm{~Hz}, 1 \mathrm{H}), 6.31(\mathrm{t}, J=6.4 \mathrm{~Hz}, 1 \mathrm{H}), 5.42(\mathrm{~m}, 1 \mathrm{H}), 5.05(\mathrm{~m}, 2 \mathrm{H}), 3.52(\mathrm{~m}$, $1 \mathrm{H}), 3.36(\mathrm{dd}, J=15.2 \mathrm{~Hz}, J=8.0 \mathrm{~Hz}, 1 \mathrm{H}), 3.20(\mathrm{~m}, 1 \mathrm{H}), 3.08(\mathrm{~m}, 1 \mathrm{H}), 2.97(\mathrm{dd}, J=17.2 \mathrm{~Hz}, J=4.8 \mathrm{~Hz}$, 1H), $2.55(\mathrm{~m}, 1 \mathrm{H}), 2.33(\mathrm{~m}, 1 \mathrm{H}), 2.04(\mathrm{~m}, 2 \mathrm{H}), 1.88(\mathrm{~s}, 3 \mathrm{H}), 1.75(\mathrm{~m}, 12 \mathrm{H}), 1.65(\mathrm{~s}, 3 \mathrm{H}), 1.62(\mathrm{~s}, 3 \mathrm{H})$, $1.58(\mathrm{~s}, 3 \mathrm{H}), 1.41(\mathrm{~m}, 6 \mathrm{H}), 1.36(\mathrm{~m}, 6 \mathrm{H}), 1.27(\mathrm{~m}, 8 \mathrm{H})$; MS (ESI, $m / z): 839.99[\mathrm{M}+\mathrm{Na}]^{+}$.

4-Butyramidophenyl gambogate (26) Yield 63\%; HPLC: 98.6\%; yellow powder; ${ }^{1} \mathrm{H}-\mathrm{NMR}\left(\mathrm{CDCl}_{3}\right): \delta$ $12.83(\mathrm{~s}, 1 \mathrm{H}), 7.51(\mathrm{~d}, J=7.2 \mathrm{~Hz}, 1 \mathrm{H}), 7.44(\mathrm{~d}, J=8.8 \mathrm{~Hz}, 2 \mathrm{H}), 7.29(\mathrm{~s}, 1 \mathrm{H}), 6.81(\mathrm{~d}, J=8.8 \mathrm{~Hz}, 2 \mathrm{H})$, $6.64(\mathrm{~m}, 1 \mathrm{H}), 6.32(\mathrm{t}, J=6.8 \mathrm{~Hz}, 1 \mathrm{H}), 5.40(\mathrm{~d}, 10.0 \mathrm{~Hz}, 1 \mathrm{H}), 5.04(\mathrm{~m}, 2 \mathrm{H}), 3.46(\mathrm{~m}, 1 \mathrm{H}), 3.33(\mathrm{dd}$, $J=14.4 \mathrm{~Hz}, J=8.0 \mathrm{~Hz}, 1 \mathrm{H}), 3.15(\mathrm{~m}, 1 \mathrm{H}), 3.07(\mathrm{~m}, 1 \mathrm{H}), 2.91(\mathrm{dd}, J=17.2 \mathrm{~Hz}, J=4.4 \mathrm{~Hz}, 1 \mathrm{H}), 2.54(\mathrm{~d}$, $J=9.2 \mathrm{~Hz}, 1 \mathrm{H}), 2.33(\mathrm{~m}, 3 \mathrm{H}), 2.01(\mathrm{~m}, 2 \mathrm{H}), 1.86(\mathrm{~s}, 3 \mathrm{H}), 1.76(\mathrm{~m}, 8 \mathrm{H}), 1.62(\mathrm{~m}, 6 \mathrm{H}), 1.55(\mathrm{~s}, 3 \mathrm{H}), 1.38$ $(\mathrm{m}, 4 \mathrm{H}), 1.30(\mathrm{~m}, 5 \mathrm{H}), 1.00(\mathrm{t}, J=7.6 \mathrm{~Hz}, 3 \mathrm{H})$; MS (ESI, $m / z): 812.78[\mathrm{M}+\mathrm{Na}]^{+}$.

2-Acetamidophenyl gambogate (27) Yield 67\%; HPLC: 98.3\%; yellow oil; ${ }^{1} \mathrm{H}-\mathrm{NMR}\left(\mathrm{CDCl}_{3}\right)$ : $\delta 12.86$ (s, 1H), $8.17(\mathrm{~d}, J=7.6 \mathrm{~Hz}, 1 \mathrm{H}), 7.49$ (d, $J=6.8 \mathrm{~Hz}, 1 \mathrm{H}), 7.46(\mathrm{~s}, 1 \mathrm{H}), 7.17(\mathrm{t}, J=7.2 \mathrm{~Hz}, 1 \mathrm{H}), 7.05$ (t, $J=7.2 \mathrm{~Hz}, 1 \mathrm{H}), 6.96(\mathrm{dd}, J=8.4 \mathrm{~Hz}, J=1.2 \mathrm{~Hz}, 1 \mathrm{H}), 6.61(\mathrm{~d}, J=10.4 \mathrm{~Hz}, 1 \mathrm{H}), 6.09(7.2 \mathrm{~Hz}, 1 \mathrm{H})$, $5.39(\mathrm{~d}, J=10.0 \mathrm{~Hz}, 1 \mathrm{H}), 5.05(\mathrm{~m}, 2 \mathrm{H}), 3.47(\mathrm{~m}, 1 \mathrm{H}), 3.32-3.21(\mathrm{~m}, 2 \mathrm{H}), 3.06-2.99(\mathrm{~m}, 2 \mathrm{H}), 2.54(\mathrm{~d}$, $J=9.2 \mathrm{~Hz}, 1 \mathrm{H}), 2.32(\mathrm{dd}, J=13.2 \mathrm{~Hz}, J=4.4 \mathrm{~Hz}, 1 \mathrm{H}), 2.17(\mathrm{~s}, 3 \mathrm{H}), 2.05$ (m, 2H), 1.91 (s, 3H), 1.76 
(s, 3H), $1.71(\mathrm{~s}, 3 \mathrm{H}), 1.65(\mathrm{~s}, 3 \mathrm{H}), 1.62(\mathrm{~s}, 3 \mathrm{H}), 1.58(\mathrm{~s}, 3 \mathrm{H}), 1.40(\mathrm{~m}, 1 \mathrm{H}), 1.37(\mathrm{~s}, 3 \mathrm{H}), 1.28(\mathrm{~m}, 4 \mathrm{H})$; MS $(\mathrm{ESI}, \mathrm{m} / \mathrm{z}): 784.71[\mathrm{M}+\mathrm{Na}]^{+}$.

3-Acetamidophenyl gambogate (28) Yield 73\%; HPLC: 99.4\%; yellow oil; ${ }^{1} \mathrm{H}-\mathrm{NMR}\left(\mathrm{CDCl}_{3}\right)$ : $\delta 13.19$ (s, 1H), $7.71(\mathrm{~d}, J=8.0 \mathrm{~Hz}, 1 \mathrm{H}), 7.56(\mathrm{~m}, 2 \mathrm{H}), 7.23(\mathrm{~d}, J=8.4 \mathrm{~Hz}, 1 \mathrm{H}), 6.61(\mathrm{~m}, 2 \mathrm{H}), 6.51(\mathrm{~s}, 1 \mathrm{H}), 6.47$ (dd, $J=7.6 \mathrm{~Hz}, J=5.2 \mathrm{~Hz}, 1 \mathrm{H}), 5.42(\mathrm{~d}, J=10.0 \mathrm{~Hz}, 1 \mathrm{H}), 5.04(\mathrm{~m}, 2 \mathrm{H}), 3.48(\mathrm{~m}, 1 \mathrm{H}), 3.35$ (dd, $J=14.8 \mathrm{~Hz}, J=8.4 \mathrm{~Hz}, 1 \mathrm{H}), 3.15(\mathrm{~m}, 2 \mathrm{H}), 2.78(\mathrm{~m}, 1 \mathrm{H}), 2.54(\mathrm{~d}, J=9.2 \mathrm{~Hz}, 1 \mathrm{H}), 2.32$ (dd, $J=13.6 \mathrm{~Hz}, J=4.8 \mathrm{~Hz}, 1 \mathrm{H}), 2.19$ (s, 3H), 2.01 (q, $J=8.0 \mathrm{~Hz}, 2 \mathrm{H}), 1.89$ (s, 3H), 1.77 (s, 3H), 1.73 $(\mathrm{s}, 3 \mathrm{H}), 1.65(\mathrm{~s}, 3 \mathrm{H}), 1.63(\mathrm{~s}, 3 \mathrm{H}), 1.60(\mathrm{~s}, 1 \mathrm{H}), 1.55(\mathrm{~s}, 3 \mathrm{H}), 1.40(\mathrm{~m}, 2 \mathrm{H}), 1.30(\mathrm{~s}, 3 \mathrm{H}), 1.29(\mathrm{~s}, 3 \mathrm{H})$; MS (ESI, $m / z): 784.79[\mathrm{M}+\mathrm{Na}]^{+}$.

S-thiazol-2-yl gambogthioate (29) Yield 68\%; HPLC: 99.2\%; yellow oil; ${ }^{1} \mathrm{H}-\mathrm{NMR}\left(\mathrm{CDCl}_{3}\right): \delta 12.79$ $(\mathrm{s}, 1 \mathrm{H}), 7.89(\mathrm{~d}, J=3.6 \mathrm{~Hz}, 1 \mathrm{H}), 7.61(\mathrm{~d}, J=6.8 \mathrm{~Hz}, 1 \mathrm{H}), 7.51(\mathrm{~d}, J=3.2 \mathrm{~Hz}, 1 \mathrm{H}), 6.69$ (m, 2H), 5.44 $(\mathrm{d}, J=10.0 \mathrm{~Hz}, 1 \mathrm{H}), 5.07(\mathrm{~m}, 2 \mathrm{H}), 3.54(\mathrm{~m}, 1 \mathrm{H}), 3.25(\mathrm{~d}, J=6.8 \mathrm{~Hz}, 2 \mathrm{H}), 2.69$ (dd, $J=15.6 \mathrm{~Hz}$, $J=7.6 \mathrm{~Hz}, 1 \mathrm{H}), 2.61(\mathrm{~d}, J=7.2 \mathrm{~Hz}, 1 \mathrm{H}), 2.56(\mathrm{~d}, J=9.6 \mathrm{~Hz}, 1 \mathrm{H}), 2.36(\mathrm{dd}, J=13.2 \mathrm{~Hz}, J=4.8 \mathrm{~Hz}$, $1 \mathrm{H}), 2.02(\mathrm{~m}, 2 \mathrm{H}), 1.73(\mathrm{~s}, 3 \mathrm{H}), 1.70(\mathrm{~s}, 3 \mathrm{H}), 1.63(\mathrm{~m}, 7 \mathrm{H}), 1.55(\mathrm{~s}, 3 \mathrm{H}), 1.47(\mathrm{~s}, 3 \mathrm{H}), 1.40(\mathrm{~m}, 5 \mathrm{H})$, $1.31(\mathrm{~s}, 3 \mathrm{H}) ; \mathrm{MS}(\mathrm{ESI}, \mathrm{m} / z): 728.54[\mathrm{M}+\mathrm{Na}]^{+}$.

4-Acetamidophenyl gambogthioate (30) Yield 59\%; HPLC: 99.5\%; yellow oil; ${ }^{1} \mathrm{H}-\mathrm{NMR}\left(\mathrm{CDCl}_{3}\right)$ : $\delta$ 12.89 (s, 1H), $7.59(\mathrm{~m}, 1 \mathrm{H}), 7.48(\mathrm{~d}, J=6.8 \mathrm{~Hz}, 1 \mathrm{H}), 7.45$ (d, $J=8.4 \mathrm{~Hz}, 2 \mathrm{H}), 7.15$ (d, $J=8.4 \mathrm{~Hz}$, 2H), $6.67(\mathrm{~d}, J=8.0 \mathrm{~Hz}, 1 \mathrm{H}), 6.02(\mathrm{t}, J=6.4 \mathrm{~Hz}, 1 \mathrm{H}), 5.42(\mathrm{~m}, 1 \mathrm{H}), 5.05(\mathrm{~m}, 2 \mathrm{H}), 3.44(\mathrm{~m}, 1 \mathrm{H}), 3.36$ (m, 1H), $3.15(\mathrm{~m}, 1 \mathrm{H}), 2.90(\mathrm{dd}, J=17.2 \mathrm{~Hz}, J=8.0 \mathrm{~Hz}, 1 \mathrm{H}), 2.79(\mathrm{~m}, 1 \mathrm{H}), 2.55$ (dd, $J=18.0 \mathrm{~Hz}$, $J=9.2 \mathrm{~Hz}, 1 \mathrm{H}), 2.28(\mathrm{dd}, J=13.2 \mathrm{~Hz}, J=4.4 \mathrm{~Hz}, 1 \mathrm{H}), 2.09(\mathrm{~s}, 3 \mathrm{H}), 2.04(\mathrm{~m}, 2 \mathrm{H}), 1.93(\mathrm{~s}, 3 \mathrm{H})$, $1.75(\mathrm{~m}, 3 \mathrm{H}), 1.69(\mathrm{~s}, 3 \mathrm{H}), 1.65(\mathrm{~s}, 3 \mathrm{H}), 1.62(\mathrm{~s}, 3 \mathrm{H}), 1.55(\mathrm{~s}, 3 \mathrm{H}), 1.47(\mathrm{~s}, 3 \mathrm{H}), 1.39(\mathrm{~m}, 3 \mathrm{H}), 1.27$ $(\mathrm{s}, 3 \mathrm{H}) ; \mathrm{MS}(\mathrm{ESI}, \mathrm{m} / z): 800.63[\mathrm{M}+\mathrm{Na}]^{+}$.

4-(4-Methoxyphenyl)thiazol-2-gambogamide (31) Yield 59\%; HPLC: 99.2\%; yellow powder; ${ }^{1} \mathrm{H}-\mathrm{NMR}\left(\mathrm{CDCl}_{3}\right): \delta 12.82(\mathrm{~s}, 1 \mathrm{H}), 10.28(\mathrm{~s}, 1 \mathrm{H}), 7.75(\mathrm{~d}, J=8.8 \mathrm{~Hz}, 2 \mathrm{H}), 7.61(\mathrm{q}, J=3.6 \mathrm{~Hz}, 1 \mathrm{H})$, $7.00(\mathrm{~d}, J=4.4 \mathrm{~Hz}), 6.91(\mathrm{~d}, J=8.8 \mathrm{~Hz}, 2 \mathrm{H}), 6.58(\mathrm{dd}, J=10 \mathrm{~Hz}, J=1.6 \mathrm{~Hz}, 1 \mathrm{H}), 5.77(\mathrm{t}, J=8 \mathrm{~Hz}$, $1 \mathrm{H}), 5.36(\mathrm{q}, J=10 \mathrm{~Hz}, 1 \mathrm{H}), 5.10-4.89(\mathrm{~m}, 2 \mathrm{H}), 3.84(\mathrm{~s}, 3 \mathrm{H}), 3.53(\mathrm{~m}, 1 \mathrm{H}), 3.07(\mathrm{~m}, 2 \mathrm{H}), 2.76(\mathrm{~m}$, 2H), $2.60(\mathrm{~m}, 1 \mathrm{H}), 2.37(\mathrm{dd}, J=13.2 \mathrm{~Hz}, J=4.4 \mathrm{~Hz}, 1 \mathrm{H}), 2.05(\mathrm{~m}, 2 \mathrm{H}), 1.95(\mathrm{~m}, 3 \mathrm{H}), 1.61(\mathrm{~m}, 9 \mathrm{H})$, $1.49(\mathrm{~m}, 8 \mathrm{H}), 1.41(\mathrm{~m}, 3 \mathrm{H}), 1.38(\mathrm{~s}, 1 \mathrm{H}), 1.27(\mathrm{~m}, 3 \mathrm{H})$; MS (ESI, $m / z): 817.52[\mathrm{M}+\mathrm{H}]^{+}$.

Thiazol-2-gambogamide (32) Yield 58\%; HPLC: 99.4\%; yellow oil; ${ }^{1} \mathrm{H}-\mathrm{NMR}\left(\mathrm{CDCl}_{3}\right)$ : $\delta 12.82$ (s, 1H), 10.20 (br, 1H), 7.57 (dd, $J=7.2 \mathrm{~Hz}, J=2.8 \mathrm{~Hz}, 1 \mathrm{H}), 7.42$ (d, $J=3.6 \mathrm{~Hz}, 1 \mathrm{H}), 6.93$ (m, 1H), $6.61(\mathrm{q}, J=4.8 \mathrm{~Hz}, 1 \mathrm{H}), 5.65(\mathrm{q}, J=8 \mathrm{~Hz}, 1 \mathrm{H}), 5.42(\mathrm{q}, J=10 \mathrm{~Hz}, 1 \mathrm{H}), 5.12-4.98(\mathrm{~m}, 2 \mathrm{H}), 3.52$ (t, $J=4.8 \mathrm{~Hz}, 1 \mathrm{H}), 3.15(\mathrm{~m}, 2 \mathrm{H}), 2.72(\mathrm{~m}, 2 \mathrm{H}), 2.56(\mathrm{~m}, 1 \mathrm{H}), 2.36(\mathrm{~m}, 1 \mathrm{H}), 2.06(\mathrm{~m}, 2 \mathrm{H}), 1.92(\mathrm{~s}, 3 \mathrm{H})$, $1.78(\mathrm{~m}, 3 \mathrm{H}), 1.64(\mathrm{~s}, 3 \mathrm{H}), 1.61(\mathrm{~m}, 6 \mathrm{H}), 1.54(\mathrm{~s}, 1 \mathrm{H}), 1.41(\mathrm{~s}, 2 \mathrm{H}), 1.37(\mathrm{~m}, 3 \mathrm{H}), 1.21(\mathrm{~m}, 6 \mathrm{H})$; $\mathrm{MS}$ $(\mathrm{ESI}, \mathrm{m} / z): 711.54[\mathrm{M}+\mathrm{H}]^{+}$.

1-Gambogyl pyrazole (33) Yield 49\%; HPLC: 99.4\%; yellow powder; ${ }^{1} \mathrm{H}-\mathrm{NMR}\left(\mathrm{CDCl}_{3}\right)$ : $\delta 12.89$ (s, $1 \mathrm{H}), 8.05(\mathrm{~m}, 1 \mathrm{H}), 7.59(\mathrm{~m}, 1 \mathrm{H}), 7.51(\mathrm{~m}, 2 \mathrm{H}), 6.68(\mathrm{dd}, J=20.8 \mathrm{~Hz}, J=9.6 \mathrm{~Hz}, 1 \mathrm{H}), 6.33(\mathrm{~m}, 1 \mathrm{H})$, $5.44(\mathrm{~m}, 1 \mathrm{H}), 5.06(\mathrm{~m}, 2 \mathrm{H}), 3.46(\mathrm{~m}, 1 \mathrm{H}), 3.43(\mathrm{~m}, 1 \mathrm{H}), 3.24(\mathrm{~m}, 3 \mathrm{H}), 2.48(\mathrm{~m}, 1 \mathrm{H}), 2.30(\mathrm{~m}, 1 \mathrm{H})$, 
$2.03(\mathrm{~m}, 2 \mathrm{H}), 1.90(\mathrm{~s}, 3 \mathrm{H}), 1.75(\mathrm{~m}, 3 \mathrm{H}), 1.65(\mathrm{~m}, 9 \mathrm{H}), 1.55(\mathrm{~s}, 3 \mathrm{H}), 1.43(\mathrm{~m}, 3 \mathrm{H}), 1.25(\mathrm{~m}, 6 \mathrm{H})$; MS (ESI, $m / z): 679.29[\mathrm{M}+\mathrm{H}]^{+}$.

$N$-(benzo[d]thiazol-2-yl) gambogamide (34) Yield 59\%; HPLC: 99.7\%; yellow powder; ${ }^{1} \mathrm{H}-\mathrm{NMR}$ $\left(\mathrm{CDCl}_{3}\right): \delta 12.82(\mathrm{~s}, 1 \mathrm{H}), 10.04(\mathrm{br}, 1 \mathrm{H}), 7.80(\mathrm{~d}, J=7.6 \mathrm{~Hz}, 1 \mathrm{H}), 7.72(\mathrm{~d}, J=8.0 \mathrm{~Hz}, 1 \mathrm{H}), 7.58(\mathrm{~d}$, $J=6.8 \mathrm{~Hz}, 1 \mathrm{H}), 7.40(\mathrm{~m}, 1 \mathrm{H}), 7.30(\mathrm{~m}, 1 \mathrm{H}), 6.52(\mathrm{~d}, J=10.4 \mathrm{~Hz}, 1 \mathrm{H}), 5.73(\mathrm{~m}, 1 \mathrm{H}), 5.25(\mathrm{dd}$, $J=10.4 \mathrm{~Hz}, J=4.0 \mathrm{~Hz}, 1 \mathrm{H}), 4.96(\mathrm{~m}, 2 \mathrm{H}), 3.53(\mathrm{~m}, 1 \mathrm{H}), 3.10(\mathrm{~m}, 2 \mathrm{H}), 2.81(\mathrm{~d}, J=8.8 \mathrm{~Hz}, 2 \mathrm{H}), 2.57$ (d, $J=9.2 \mathrm{~Hz}, 1 \mathrm{H}), 2.37(\mathrm{dd}, J=13.6 \mathrm{~Hz}, J=4.4 \mathrm{~Hz}, 1 \mathrm{H}), 1.95(\mathrm{~m}, 2 \mathrm{H}), 1.85(\mathrm{~s}, 3 \mathrm{H}), 1.68(\mathrm{~m}, 3 \mathrm{H})$, $1.61(\mathrm{~s}, 3 \mathrm{H}), 1.57(\mathrm{~s}, 3 \mathrm{H}), 1.50(\mathrm{~s}, 3 \mathrm{H}), 1.45(\mathrm{~s}, 3 \mathrm{H}), 1.38(\mathrm{~m}, 5 \mathrm{H}), 1.23(\mathrm{~m}, 4 \mathrm{H})$; MS (ESI, $m / z)$ : $761.69[\mathrm{M}+\mathrm{H}]^{+}$.

$N$-(4-acetamidophenyl) gambogamide (35) Yield 73\%; HPLC: 98.6\%; yellow powder; ${ }^{1} \mathrm{H}-\mathrm{NMR}$ $\left(\mathrm{CDCl}_{3}\right): \delta 12.85(\mathrm{~s}, 1 \mathrm{H}), 8.80(\mathrm{~s}, 1 \mathrm{H}), 7.56(\mathrm{~m}, 3 \mathrm{H}), 7.43(\mathrm{~d}, J=9.2 \mathrm{~Hz}, 2 \mathrm{H}), 7.38(\mathrm{~s}, 1 \mathrm{H}), 6.67(\mathrm{~d}$, $J=10.4 \mathrm{~Hz}, 1 \mathrm{H}), 5.46(\mathrm{~d}, J=10.4 \mathrm{~Hz}, 1 \mathrm{H}), 5.31(\mathrm{t}, J=8.8 \mathrm{~Hz}, 1 \mathrm{H}), 5.04(\mathrm{~m}, 2 \mathrm{H}), 3.52(\mathrm{~m}, 1 \mathrm{H}), 3.29$ (dd, $J=14.8 \mathrm{~Hz}, J=8.0 \mathrm{~Hz}, 1 \mathrm{H}), 3.14(\mathrm{~m}, 1 \mathrm{H}), 2.81(\mathrm{dd}, J=15.2 \mathrm{~Hz}, J=9.2 \mathrm{~Hz}, 1 \mathrm{H}), 2.57(\mathrm{~d}, J=9.2 \mathrm{~Hz}, 1 \mathrm{H})$, $2.34(\mathrm{~m}, 2 \mathrm{H}), 2.15(\mathrm{~s}, 3 \mathrm{H}), 2.02(\mathrm{~m}, 2 \mathrm{H}), 1.89(\mathrm{~s}, 3 \mathrm{H}), 1.80(\mathrm{~m}, 2 \mathrm{H}), 1.70(\mathrm{~m}, 6 \mathrm{H}), 1.65(\mathrm{~s}, 3 \mathrm{H}), 1.62(\mathrm{~s}$, $3 \mathrm{H}), 1.55(\mathrm{~s}, 3 \mathrm{H}), 1.44(\mathrm{~m}, 4 \mathrm{H}), 1.36(\mathrm{~s}, 3 \mathrm{H})$; MS (ESI, $m / z): 761.83[\mathrm{M}+\mathrm{H}]^{+}$.

(32,33),(37,38)-Diepoxy- $N$-(4-acetamidophenyl) gambogamide (36). To a stirred solution of 35 (31 $\mathrm{mg}, 0.04 \mathrm{mmol})$ in $\mathrm{CH}_{2} \mathrm{Cl}_{2}(5 \mathrm{~mL})$ at $25^{\circ} \mathrm{C}, \mathrm{m}$-CPBA $(16 \mathrm{mg}, 0.09 \mathrm{mmol})$ was added. The resulting mixture was stirred for $6 \mathrm{~h}$ at $25{ }^{\circ} \mathrm{C}$. The mixture was condensed. The residue was subjected to silica gel column chromatography (petrolum ether-acetone $=3: 1$ ) to provide 36. Yield 71\%; HPLC: 99.4\%; yellow oil; ${ }^{1} \mathrm{H}-\mathrm{NMR}\left(\mathrm{CDCl}_{3}\right)$ : $\delta 12.89(\mathrm{~s}, 1 \mathrm{H}), 8.75(\mathrm{~s}, 1 \mathrm{H}), 7.60-7.39(\mathrm{~m}, 6 \mathrm{H}), 6.70(\mathrm{~m}, 1 \mathrm{H}), 5.47(\mathrm{~m}$, $1 \mathrm{H}), 5.31(\mathrm{~m}, 1 \mathrm{H}), 3.53(\mathrm{t}, J=5.2 \mathrm{~Hz}, 1 \mathrm{H}), 2.90-2.70(\mathrm{~m}, 6 \mathrm{H}), 2.60(\mathrm{~m}, 2 \mathrm{H}), 2.34(\mathrm{~m}, 2 \mathrm{H}), 2.16(\mathrm{~s}, 3 \mathrm{H})$, $1.87(\mathrm{~s}, 3 \mathrm{H}), 1.65(\mathrm{~m}, 6 \mathrm{H}), 1.47(\mathrm{~s}, 3 \mathrm{H}), 1.35(\mathrm{~m}, 6 \mathrm{H}), 1.28(\mathrm{~m}, 9 \mathrm{H}) ; \mathrm{MS}(\mathrm{ESI}, \mathrm{m} / z): 815.53[\mathrm{M}+\mathrm{Na}]^{+}$.

\subsection{Biological General Methods}

\subsubsection{Zebrafish Embryo Assay}

Using transgenic fli-1: enhanced GFP zebrafish embryos, we investigated the effects of all compounds on angiogenesis. Zebrafish embryos were generated by natural pairwise mating and raised at $28.5{ }^{\circ} \mathrm{C}$ in embryo water $(0.2 \mathrm{~g} / \mathrm{L}$ of Instant Ocean Salt in distilled water). At about $6 \mathrm{~h}$ post fertilization (hpf), the embryos were sorted in the 6-well plate (six embryos/well), removing dead and unhealthy embryos. Then the embryos were treated with the indicated concentrations of compounds which were added into embryo water. After incubation for 24 or $48 \mathrm{~h}$, the embryos were anesthetized using $0.05 \%$ 2-phenoxyethanol in embryo water, quantified and photographed.

\subsubsection{Cell Culture}

HepG2, HCT116, HeLa and LO2 cell lines were cultured in DMEM containing 10\% fetal bovine serum (FBS), $100 \mathrm{IU} / \mathrm{mL}$ penicillin and $100 \mathrm{~g} / \mathrm{mL}$ streptomycin; A549 and $\mathrm{K} 562$ cell lines were cultured in RPMI 1640 medium containing 10\% fetal bovine serum (FBS), $100 \mathrm{IU} / \mathrm{mL}$ penicillin and $100 \mathrm{~g} / \mathrm{mL}$ streptomycin; Human umbilical vein endothelial cells (HUVECs) were cultured on 
gelatin-coated culture flasks in M-199 medium with 20\% fetal bovine serum (FBS), $2 \mathrm{ng} / \mathrm{mL}$ VEGF, $10 \mathrm{ng} / \mathrm{mL}$ basic FGF, $100 \mathrm{IU} / \mathrm{mL}$ penicillin, and $100 \mu \mathrm{g} / \mathrm{mL}$ streptomycin; all of them were obtained from the American Type Culture Collection (ATCC) and all cell lines were incubated in an atmosphere of $5 \% \mathrm{CO}_{2}$ at $37^{\circ} \mathrm{C}$.

\subsubsection{Wound-Healing Assay}

HUVECs were seeded in 6-well plates precoated with $0.1 \%$ gelatin, and grown overnight to confluence. The monolayer cells were wounded by scratching with $10 \mu \mathrm{L}$ pipet tips and washed twice with serum-free DMEM (Dulbecco's modified eagle medium) to remove the nonadherent cells and then replaced by serum-free DMEM with the indicated concentrations of compounds for $24 \mathrm{~h}$. Images were taken at $0 \mathrm{~h}$ and $24 \mathrm{~h}$ independently after incubation at $37{ }^{\circ} \mathrm{C}, 5 \% \mathrm{CO}_{2}$ environment. The migrated HUVECs were manually counted. The values were observed from four randomly selected fields.

\subsubsection{Tube Formation Assay}

Matrigel was dissolved at $4{ }^{\circ} \mathrm{C}$ overnight. Each well of prechilled 96-well plates was coated with $50 \mu \mathrm{L}$ of Matrigel, incubated and solidified at $37{ }^{\circ} \mathrm{C}$ for $45 \mathrm{~min}$. After removing the unsolidified fluid, HUVECs at the density of $1 \times 10^{4}$ were cultured in DMEM containing the indicated concentrations of compounds for $6 \mathrm{~h}$. Controls were treated with the DMEM alone. Images were digitally captured and quantitatively analyzed (Olympus). The numbers and line lengths of the circular tubules formed by the cells were calculated manually. The values were observed from five randomly selected fields.

\subsubsection{MTT Assay}

Cells were treated with various concentrations of compound in 96-well culture plates for $24 \mathrm{~h}$ in final volumes of $200 \mu \mathrm{L}\left(5 \times 10^{3}\right.$ cells/well $)$. Then $20 \mu \mathrm{L}$ of MTT solution $(5 \mathrm{mg} / \mathrm{mL})$ was added to each well, and cells were incubated for an additional $3 \mathrm{~h}$. Then the medium was carefully removed, and precipitates were dissolved in $150 \mu \mathrm{L}$ of DMSO, shaken mechanically for $30 \mathrm{~min}$, and then absorbance values at a wavelength of $570 \mathrm{~nm}$ were taken on a spectrophotometer (Molecular Devices, Sunnyvale, CA, USA). Values were calculated using percentage of growth versus untreated control. The $\mathrm{IC}_{50}$ was defined as the concentration that caused $50 \%$ inhibition of cell proliferation, and was calculated by SAS statistical software.

\section{Conclusions}

In conclusion, 36 GA derivatives possessed different antiangiogenic activities. Derivatives 4, 32, 35, 36 blocked the new blood vessels from the dorsal aorta in the zebrafish embryos assay, exhibited strong inhibitory effects on the migration, tube formation and proliferation of HUVECs, additionally they showed relatively lower toxicities to zebrafish and LO2 cell line than GA. The four compounds were also capable to effectively inhibit the five tumor cell lines tested (A549, HepG2, HCT116, K562 and HeLa). Given the results of this comprehensive research, we found that compound $\mathbf{3 6}$ was the most potent one and may serve as a potential new antiangiogenesis candidate. 


\section{Acknowledgments}

We are grateful to the National Key Programs of China during the 12th Five-Year Plan Period (2012ZX09103101-033).

\section{Conflict of Interest}

The authors declare no conflict of interest.

\section{References and Notes}

1. Harris, A.L. Angiogenesis as a new target for cancer control. Eur. J. Cancer Suppl. 2003, 1, 1-12.

2. Schmidt, J.M.; Tremblay, G.B.; Pagé, M.; Mercure, J.; Feher, M.; Dunn-Dufault, R.; Peter, M.G.; Redden, P.R. Synthesis and Evaluation of a Novel Nonsteroidal-Specific Endothelial Cell Proliferation Inhibitor. J. Med. Chem. 2003, 46, 1289-1292.

3. Wong, M.L.H.; Prawira, A.; Kaye, A.H.; Hovens, C.M. Tumour angiogenesis Its mechanism and therapeutic implications in malignant gliomas. J. Clin. Neurosci. 2009, 16, 1119-1130.

4. Noguer, O.; Villena, J.; Lorita, J.; Vilaro, S.; Reina, M. Syndecan-2 downregulation impairs angiogenesis in human microvascular endothelial cells. Exp. Cell. Res. 2009, 315, 795-808.

5. Kondo, T.; Ohta, T.; Igura, K.; Hara, Y.; Kaji, K. Tea catechins inhibit angiogenesis in vitro, measured by human endothelial cell growth, migration and tube formation, through inhibition of VEGF receptor binding. Cancer Lett. 2002, 180, 139-144.

6. Carmeliet, P. Angiogenesis in health and disease. Nat. Med. 2003, 9, 653-660.

7. Jansen, M.; Hamer, P.C.D.W.; Witmer, A.N.; Troost, D.; Noorden, C.J.F.V. Current perspectives on antiangiogenesis strategies in the treatment of malignant gliomas. Brain Res. Rev. 2004, 45, 143-163.

8. Farinelle, S.; Malonne, H.; Chaboteaux, C.; Decaestecker, C.; Dedecker, R.; Gras, T.; Darro, F.; Fontaine, J.; Atassi, G.; Kiss, R. Characterization of TNP-470-induced modifications to cell functions in HUVEC and cancer cells. J. Pharmacol. Toxicol. 2000, 43, 15-24.

9. Baldessari, D.; Mione, M. How to create the vascular tree (Latest) help from the zebrafish. Pharmaco. Therapeut. 2008, 118, 206-230.

10. Sumanas, S.; Lin, S. Zebrafish as a model system for drug target screening and validation. Drug Disc Today: TARGETS 2004, 3, 89-96.

11. Ma, L.; Chen, J.Y.; Wang, X.W.; Liang, X.L.; Luo, Y.F.; Zhu, W.; Wang, T.E.; Peng, M.; Li, S.C.; Shi, J.; Peng, A.H.; Wei, Y.Q.; Chen, L.J. Structural Modification of Honokiol, a Biphenyl Occurring in Magnolia officinalis the Evaluation of Honokiol Analogues as Inhibitors of Angiogenesis and for Their Cytotoxicity and Structure Activity Relationship. J. Med. Chem. 2011, 54, 6469-6481.

12. Lele, Z.; Krone, P.H. The zebrafish as a model system in developmental, toxicological and transgenic research. Biotechnol. Adv. 1996, 14, 57-72.

13. Xie, H.; Qin, Y.X.; Zhou, Y.L.; Tong, L.J.; Lin, L.P.; Geng, M.Y.; Duan, W.H.; Ding, J. GA3, a new gambogic acid derivative, exhibits potent antitumor activities in vitro via apoptosis-involved mechanisms. Acta Pharmacol. Sin. 2009, 30, 346-354. 
14. Qiang, L.; Yang, Y.; You, Q.D.; Ma, Y.J.; Yang, L.; Nie, F.F.; Gu, H.Y.; Zhao, L.; Lu, N.; Qi, Q.; Liu, W.; Wang, X.T.; Guo, Q.L. Inhibition of glioblastoma growth and angiogenesis by gambogic acid An in vitro and in vivo study. Biol. Pharm. 2008, 75, 1083-1092.

15. Lu, N.; Yang, Y.; You, Q.D.; Ling, Y.; Gao, Y.; Gu, H.Y.; Zhao, L.; Wang, X.T.; Guo, Q.L. Gambogic acid inhibits angiogenesis through suppressing vascular endothelial growth factor-induced tyrosine phosphorylation of KDRFlk-1. Cancer Lett. 2007, 258, 80-89.

16. Yi, T.F.; Yi, Z.F.; Cho, S.G.; Luo, J.; Pandey, M.K.; Aggarwal, B.B.; Liu, M.Y. Gambogic Acid Inhibits Angiogenesis and Prostate Tumor Growth by Suppressing Vascular Endothelial Growth Factor Receptor 2 Signaling. Cancer Res. 2008, 68, 1843-1850.

17. Guo, Q.L.; Qi, Q.; You, Q.D.; Gu, H.Y.; Zhao, L.; Wu, Z.Q. Toxicological Studies of Gambogic Acid and its Potential Targets in Experimental Animals. Basic Clin. Pharmacol. Toxicol. 2006, 99, 178-184.

18. Qi, Q.; You, Q.D.; Gu, H.Y.; Zhao, L.; Liu, W.; Lu, N.; Guo, Q.L. Studies on the toxicity of gambogic acid in rats. J. Ethnopharmacol. 2008, 117, 433-438.

19. Jang, S.W.; Okada, M.; Sayeed, I.; Xiao, G.; Stein, D.; Jin, P.; Ye, K.Q. Gambogic amide, a selective agonist for TrkA receptor that possesses robust neurotrophic activity, prevents neuronal cell death-2007. Proc. Natl. Acad. Sci. USA 2007, 104, 16329-16334.

20. Guo, Q.L.; Zhao, L.; You, Q.D. Gambogic Acid Inducing Apoptosis in Human Gastric Adenocarcinom SGC-7901 Cells. Chin. J. Nat. Med. 2004, 2, 106-110.

21. Wang, J.X.; Zhao, L.; Hu, Y.; Guo, Q.L.; Zhang, L.; Wang, X.J.; Li, N.G.; You, Q.D. Studies on chemical structure modification and biology of a natural product, Gambogic acid (I) Synthesis and biological evaluation of oxidized analogues of gambogic acid. Eur. J. Med. Chem. 2009, 44, 2611-2620.

22. Zhang, H.Z.; Kasibhatla, S.; Wang, Y.; Herich, J.; Guastella, J.; Tseng, B.; Drewe, J.; Cai, S.X. Discovery, characterization and SAR of gambogic acid as a potent apoptosis inducer by a HTS assay. Bioorg. Med. Chem. 2004, 12, 309-317.

23. Udvadia, A.J.; Linney, E. Windows into development historic, current, and future perspectives on transgenic zebrafish. Dev. Biol. 2003, 256, 1-17.

24. Park, Y.J.; Lee, T.; Ha, J.; Jung, I.M.; Chung, J.K.; Kim, S.J. Effect of nicotine on human umbilical vein endothelial cells (HUVECs) migration and angiogenesis. Vasc. Pharmacol. 2008, 49, 32-36.

25. Yang, S.P.; Cai, Y.J.; Zhang, B.L.; Tong, L.J.; Xie, H.; Wu, Y.; Lin, L.P.; Ding, J.; Yue, J.M. Structural Modification of an Angiogenesis Inhibitor Discovered from Traditional Chinese Medicine and a Structure-Activity Relationship Study. J. Med. Chem. 2008, 51, 77-85.

Sample Availability: Samples of the compounds 1-36 are available from the authors.

(C) 2012 by the authors; licensee MDPI, Basel, Switzerland. This article is an open access article distributed under the terms and conditions of the Creative Commons Attribution license (http://creativecommons.org/licenses/by/3.0/). 